OPEN ACCESS

Edited by:

Nicola Maggio,

The Chaim Sheba Medical Center,

Israel

Reviewed by: Johannes Hirrlinger, Leipzig University, Germany

Eldi Schonfeld-Dado,

Stanford University, USA

${ }^{*}$ Correspondence: Zhengyu Cao zycao1999@hotmail.com Junping Kou

junpingkou@cpu.edu.cn

Received: 14 December 2016 Accepted: 03 March 2017 Published: 14 March 2017

Citation:

Wang Y, Xu Y, Liu Q, Zhang Y, Gao Z, Yin $M$, Jiang N, Cao G, Yu B, Cao Z and Kou J (2017) Myosin IIA-related Actomyosin Contractility Mediates

Oxidative Stress-induced Neuronal Apoptosis.

Front. Mol. Neurosci. 10:75 doi: 10.3389/fnmol.2017.00075

\section{Myosin IIA-related Actomyosin Contractility Mediates Oxidative Stress-induced Neuronal Apoptosis}

\author{
Yan Wang ${ }^{1}$, Yingqiong Xu ${ }^{1}$, Qian Liu $^{2}$, Yuanyuan Zhang ${ }^{1}$, Zhen Gao ${ }^{3}$, Mingzhu Yin ${ }^{4}$, \\ Nan Jiang ${ }^{1}$, Guosheng $\mathrm{CaO}^{1}$, Boyang Yu ${ }^{1}$, Zhengyu Cao ${ }^{1 *}$ and Junping Kou ${ }^{1 *}$ \\ 'State Key Laboratory of Natural Products, Jiangsu Key Laboratory of TCM Evaluation and Translational Research, \\ Department of Complex Prescription of TCM, China Pharmaceutical University, Nanjing, China, ${ }^{2}$ Department of Neurology, \\ Jinling Hospital, Nanjing University School of Medicine, Nanjing, China, ${ }^{3}$ Department of Medicine-Ather and Lipo, \\ Baylor College of Medicine, Houston, TX, USA, " Department of Pathology, Yale School of Medicine, New Haven, CT, USA
}

Oxidative stress-induced neuronal apoptosis plays an important role in the progression of central nervous system (CNS) diseases. In our study, when neuronal cells were exposed to hydrogen peroxide $\left(\mathrm{H}_{2} \mathrm{O}_{2}\right)$, an exogenous oxidant, cell apoptosis was observed with typical morphological changes including membrane blebbing, neurite retraction and cell contraction. The actomyosin system is considered to be responsible for the morphological changes, but how exactly it regulates oxidative stress-induced neuronal apoptosis and the distinctive functions of different myosin II isoforms remain unclear. We demonstrate that myosin IIA was required for neuronal contraction, while myosin IIB was required for neuronal outgrowth in normal conditions. During $\mathrm{H}_{2} \mathrm{O}_{2}$-induced neuronal apoptosis, myosin $\mathrm{IA}$, rather than IIB, interacted with actin filaments to generate contractile forces that lead to morphological changes. Moreover, myosin IIA knockout using clustered regularly interspaced short palindromic repeats/CRISPR-associated protein-9 nuclease (CRISPR/Cas9) reduced $\mathrm{H}_{2} \mathrm{O}_{2}$-induced neuronal apoptosis and the associated morphological changes. We further demonstrate that caspase-3/Rho-associated kinase 1 (ROCK1) dependent phosphorylation of myosin light chain (MLC) was required for the formation of the myosin IIA-actin complex. Meanwhile, either inhibition of myosin II ATPase with blebbistatin or knockdown of myosin IIA with siRNA reversely attenuated caspase-3 activation, suggesting a positive feedback loop during oxidative stress-induced apoptosis. Based on our observation, myosin IIA-actin complex contributes to actomyosin contractility and is associated with the positive feedback loop of caspase-3/ROCK1/MLC pathway. This study unravels the biochemical and mechanistic mechanisms during oxidative stress-induced neuronal apoptosis and may be applicable for the development of therapies for CNS diseases.

Keywords: oxidative stress, neuronal apoptosis, myosin IIA, myosin IIB, actomyosin contractility, positive feedback loop

Abbreviations: CNS, central nervous system; CRISPR/Cas9, clustered regularly interspaced short palindromic repeats/CRISPRassociated protein-9 nuclease; DMSO, dimethyl sulfoxide; $\mathrm{H}_{2} \mathrm{O}_{2}$, hydrogen peroxide; MAP2, microtubule-associated protein 2; MHC, myosin heavy chain; MLC, myosin light chain; Myosin II, non-muscle myosin II; MLCK, myosin light chain kinase; MLCP, myosin light chain phosphatase; MTT, 3-(4,5-dimethylthiazol-2-yl)-2,5-diphenyl tetrazolium bromide; NAC, N-acetyl-L-cysteine; ROCK, Rho-associated kinase; TEM, transmission electron microscopy. 


\section{INTRODUCTION}

Oxidative stress-induced neuronal apoptosis has been implicated in many central nervous system (CNS) diseases, including Alzheimer's diseases, stroke and schizophrenia (Hayashi-Takagi et al., 2014; Volpe and Paneni, 2015; Kamat et al., 2016). One of the major pathological features of these neuronal disorders is the dysfunction of cytoskeleton, which influences synapse formation and maturation, vesicle/organelle trafficking, axon regeneration and spine morphology (Schafer et al., 2009; Gordon-Weeks and Fournier, 2014; Hayashi-Takagi et al., 2014). It has been demonstrated that the actomyosin system is responsible for the structural and morphological changes during the execution of apoptosis, such as dynamic cell contraction, membrane blebbing and chromatin condensation (Croft et al., 2005; Even-Ram et al., 2007; Ndozangue-Touriguine et al., 2008). The actomyosin system consists of actin filaments and myosin. Among the members of the myosin family, myosin II motor protein has been implicated in producing the forces responsible for cellular contraction (Landino and Ohi, 2016). Myosin II is a hexameric polypeptide, comprised of two myosin heavy chains (MHC) and two sets of myosin light chains (MLC). The N-terminal globular motor domain of MHC uses the energy of ATP hydrolysis to generate force and move along actin filaments, while C-terminal tail region interacts with other MHCs to form anti-parallel thick filaments (Bresnick, 1999; Hartman and Spudich, 2012). In the CNS, myosin II has been demonstrated to regulate neuronal morphogenesis (Ozkan et al., 2015), migration (Solecki et al., 2009), axon outgrowth (Pool et al., 2011), as well as growth cone motility (Medeiros et al., 2006). However, how exactly the actomyosin system regulates oxidative stress-induced neuronal apoptosis remains unclear.

There are two major isoforms of myosin II in neuronal cells, myosin IIA and IIB, which are encoded by Myh9 and Myh10, respectively (Simons et al., 1991). Due to a high degree of homology in the amino acid sequences of their heavy chains, myosin IIA and IIB have overlapping cellular functions (Wylie and Chantler, 2001). However, they also display different catalytic activities, molecular interactions, tissue and intracellular distributions (Vicente-Manzanares et al., 2007; Zhou and Wang, 2008). Myosin IIB is the predominate isoform in the nervous system, driving neurite outgrowth processes (Rex et al., 2010; Yu et al., 2012), and modulating dendritic spines morphology and synaptic function (Ryu et al., 2006), while myosin IIA is required in maintaining tensile adhesion (Wylie and Chantler, 2001) and neurite retraction (Wylie and Chantler, 2003). In our previous studies, we have demonstrated that the neuroprotective mechanism of Ginsenoside $\mathrm{Rg} 1$ is associated with the inhibition of myosin IIA-actin interaction (Wang et al., 2016). However, little knowledge is available on the distinct roles of myosin II isoforms in oxidative stress-induced neuronal apoptosis. We are interested to investigate how myosin II isoforms regulate neuronal apoptosis.

Moreover, the actin-myosin interaction is highly regulated by the phosphorylation of the regulatory MLC, through MLC kinase (MLCK), MLC phosphatase and Rho-associated protein kinase (ROCK1 and ROCK2; Nilius et al., 2000; Totsukawa et al., 2000). ROCK is a serine/threonine protein kinase that directly phosphorylates MLC or indirectly increases MLC phosphorylation by inactivating myosin light chain phosphatase (MLCP). Activated Rho binds to ROCK and disrupts the negative regulatory sequence between the kinase domain and the autoinhibitory region, resulting in a truncated active form (Kimura et al., 1996; Eitaki et al., 2012). In addition, only ROCK1 can be cleaved by caspase-3, generating active kinase to induce apoptosis (Coleman et al., 2001). Inhibition of ROCK or caspase activity abrogates MLC phosphorylation and apoptotic membrane blebbing in astrocytes and TF-1 cells (Lai et al., 2003; Miñambres et al., 2006). We have previously illustrated the caspase-3/ROCK1/MLC feedback loop in hydrogen peroxide $\left(\mathrm{H}_{2} \mathrm{O}_{2}\right)$-induced PC12 cells injury (Shen et al., 2015a), but the correlation between myosin II and the positive feedback loop remains unknown.

Our study focuses on the distinctive contribution of myosin IIA and IIB in $\mathrm{H}_{2} \mathrm{O}_{2}$-induced neuronal apoptosis and the related mechanisms. We demonstrate that myosin IIA displays a distinctive role in the formation of functional contractile cytoskeleton that is required for apoptotic membrane blebbing and neurite retraction, whereas myosin IIB drives the neuronal outgrowth processes. The myosin IIA-actin interaction regulates caspase-3/ROCK1/MLC signal cascade by a feedback mechanism upon oxidative stress. These data indicate that myosin II isoforms function differently in cytoskeletal reorganization and only myosin IIA functions in positive feedback loop pathway in neuronal apoptosis. It provides new insights on the mechanisms of oxidative stress-induced neuronal apoptosis and paves the way for development of better treatments for neuronal diseases.

\section{MATERIALS AND METHODS}

\section{Material}

L-glutamine, Neurobasal medium, B-27 supplement $(50 \times$, minus antioxidants), soybean trypsin inhibitor, Dulbecco's modified Eagle's medium (DMEM), Opti-modified Eagle's medium ${ }^{\circledR} \quad\left(\right.$ Opti-MEM $\left.{ }^{\circledR}\right), \quad$ Lipofectamine ${ }^{\circledR} \quad$ RNAiMAX, Lipofectamine ${ }^{\circledR}$ 3000, Alexa Fluor ${ }^{\circledR} 488$ donkey anti-rabbit antibody and Alexa Fluor ${ }^{\circledR} 568$ phalloidin were obtained from Thermo Fisher Scientific (San Jose, CA, USA). Fetal bovine serum was from ScienCell (San Diego, CA, USA). Penicillin, streptomycin and 3-(4,5-dimethylthiazol-2-yl)-2,5-diphenyl tetrazolium bromide (MTT) were purchased from Amresco (Solon, OH, USA). DNase, cytosine arabinoside, poly-L-lysine, $\mathrm{N}$-acetyl-L-cysteine (NAC), blebbistatin, cytochalasin D, ML-7 and $\mathrm{H}_{2} \mathrm{O}_{2}$ and were from Sigma-Aldrich (St. Louis, MO, USA). Y27632, z-VAD-fmk and z-DEVD-fmk were from Selleck Chemicals (Houston, TX, USA). Anti-MLC, anti-P-MLC (Ser19), anti-caspase-3, anti-microtubule-associated protein 2 (MAP2) antibodies were from Cell Signaling Technology (Danvers, MA, USA). Anti-myosin IIA and anti-actin antibodies were from Abcam (Cambridge, UK). Anti-ROCK1 and anti-ROCK2 antibodies, Protein A/G PLUS-Agarose, normal rabbit IgG and normal mouse IgG were from Santa Cruz Biotechnology (Dallas, TX, USA). Anti-GAPDH antibody was 
purchased from KangCheng (Shanghai, China). HRP-conjugated secondary antibodies were from Boster (Wuhan, China). DAPI was from Beyotime Biotech (Haimen, China). Protease inhibitor cocktail, RIPA buffer and ECL were purchased from Vazyme Biotech (Nanjing, China). Dimethyl sulfoxide (DMSO) was obtained from SunShineBio (Nanjing, China).

\section{Cell Culture}

Highly differentiated PC12 (rat adrenal pheochromocytoma) cells were purchased from Shanghai Institute of Cell Biology, Chinese Academy of Sciences. According to the protocol from Shanghai Institute of Cell Biology, PC12 cells were differentiated in differentiation medium (DMEM with $100 \mathrm{ng} / \mathrm{ml}$ nerve growth factor) for 5-7 days to induce neurite formation and differentiation. The media was changed with new differentiation medium every 2-3 days. The differentiated PC12 cells were cultured in DMEM, supplemented with $10 \%$ fetal bovine serum, $100 \mathrm{I} . \mathrm{U} . / \mathrm{mL}$ penicillin and $100 \mu \mathrm{g} / \mathrm{mL}$ streptomycin, in a humidified cell culture incubator in $5 \% \mathrm{CO}_{2}$ atmosphere at $37^{\circ} \mathrm{C}$.

\section{Primary Cortical Neurons Cultures}

Primary cultures of cortical neurons were obtained from Sprague-Dawley rats on embryonic day 16-17 and processed as described (Cao et al., 2015). The pregnant SpragueDawley rats were provided by the Reference Animal Research Centre of Yangzhou University (Yangzhou, China; certificate no SCXK 2014-0004). The pregnant rats were euthanized by $\mathrm{CO}_{2}$ asphyxiation, and embryos were removed under sterile conditions. Neocortices were collected, removed of their meninges, minced by trituration with a Pasteur pipette, and digested in trypsin at $37^{\circ} \mathrm{C}$ for $25 \mathrm{~min}$. The cells were further dissociated by two successive trituration and sedimentation steps in isolation buffer containing soybean trypsin inhibitor and DNase. The cells were then centrifuged and resuspended in Eagle's minimal essential medium with Earle's salt (MEM), supplemented with $2 \mathrm{mM}$ L-glutamine, $10 \%$ fetal bovine serum, 100 I.U./mL penicillin and $100 \mu \mathrm{g} / \mathrm{mL}$ streptomycin, $\mathrm{pH}$ 7.4. The dissociated cells were plated onto poly-L-lysinecoated 96-well culture plates or 6-well culture plates at a density of $1 \times 10^{6}$ cells $/ \mathrm{mL}$. For the immune-fluorescent experiments, cells were plated onto poly-L-lysine-coated $35-\mathrm{mm}$ confocal dishes (Glass Bottom Dish) at a density of $2 \times 10^{5}$ cells $/ \mathrm{mL}$. Cells were cultured at $37^{\circ} \mathrm{C}$ in a $5 \% \quad \mathrm{CO}_{2}$ and 95\% humidity atmosphere. Cells were treated with Cytosine arabinoside $(10 \mu \mathrm{M})$ after $24-48 \mathrm{~h}$ post plating to prevent proliferation of non-neuronal cells. The culture medium was changed every 3 days using Neurobasal medium supplemented with B-27 supplement (minus antioxidants), $2 \mathrm{mM}$ L-glutamine, 100 I.U./mL penicillin and $100 \mu \mathrm{g} / \mathrm{mL}$ streptomycin, $\mathrm{pH} 7.4$. The cultures were used for experiments between 7 and 9 DIV (days in vitro). This study was carried out in accordance with the National Institutes of Health Guide for the care and use of laboratory animals. Animal experiments and surgical procedures were approved by the Animal Ethics Committee of the School of Chinese Materia Medica, China Pharmaceutical University.

\section{Cell Treatment}

Cells were treated with NAC $(500 \mu \mathrm{M})$, blebbistatin $(1 \mu \mathrm{M})$, cytochalasin D (1 $\mu \mathrm{M}), \mathrm{ML}^{-7}(5 \mu \mathrm{M}), \mathrm{Y} 27632(10 \mu \mathrm{M})$, $\mathrm{z}$-VAD-fmk $(10 \mu \mathrm{M})$ or $\mathrm{z}$-DEVD-fmk $(10 \mu \mathrm{M})$ for $1 \mathrm{~h}$, followed by co-incubating with $100 \mu \mathrm{M} \mathrm{H}_{2} \mathrm{O}_{2}$ for another $12 \mathrm{~h}$. All compounds were dissolved in DMSO and finally diluted in the serum free medium with DMSO at the final concentration of $0.1 \%$. DMSO was added in the control groups.

\section{siRNA Transfection}

The siRNA oligonucleotides used to knockdown myosin IIA or IIB were purchased from Biomics Biotech (Nantong, China). The antisense sequence for myosin IIA (Myh9) is $5^{\prime}$-GAGACAAUGGAGGCCAUGA-3'. The antisense sequence for myosin IIB (Myh10) is $5^{\prime}$-CUAUUCAGGACUCAUCUAU$3^{\prime}$. PC12 cells growing on 6 -well plates at 50\%-60\% confluency were transfected with $5 \mu \mathrm{g}$ of siRNA and $5 \mu \mathrm{L}$ of Lipofectamine ${ }^{\circledR}$ RNAiMAX in the Opti-MEM ${ }^{\circledR}$ medium. The cells were incubated with the medium containing siRNA for $6 \mathrm{~h}$. The transfection medium was then replaced with complete medium without antibiotics. Cells were processed for analysis $48-72 \mathrm{~h}$ after transfection.

\section{Generation of Myh9 Knockout Cells Using CRISPR/Cas9 System}

MYH9 clustered regularly interspaced short palindromic repeats/CRISPR-associated protein-9 nuclease (CRISPR/Cas9) knockout plasmid (Santa Cruz Biotechnology, Dallas, TX, USA) consists of a pool of three plasmids, encoding three guide RNAs (gRNAs) to target different regions of Myh9 gene for maximum knockout efficiency. The gRNAs sequences targeted by Myh9 CRISPR plasmids are 5'-TGGTTCAAAGCCATTCTT GG-3', 5' -ACCAGCCAGCCTTAAGGAGG-3' and 5' -TATCTA CTCAGAGGAGATCG-3'. Control CRISPR/Cas9 Plasmid does not recognize any DNA sequence used as a negative control (NC). Each plasmid encodes Cas9 nuclease and green fluorescent protein (GFP). PC12 cells were seeded in 6-well plates (at a density of $1 \times 10^{6}$ cells/well) the day before transfection. Cells were transfected with $2 \mu \mathrm{g}$ of the plasmid using lipofectamine $300{ }^{\circledR}$. After incubation of 72 h, GFP-positive cells were sorted and grown as single cell in 96-well plates using the BD FACSAria III cell sorter (BD Biosciences, San Jose, CA, USA). Colonies derived from single cells were expanded in media with $20 \%$ FBS. After 3 weeks, Myh9 knockout cells were screened by Western blotting using myosin IIA-specific antibodies.

\section{Cell Viability}

Cell viability was determined by the MTT assay. Cells were seeded in 96-well plates and cultured at $37^{\circ} \mathrm{C}$ in an atmosphere of $5 \% \mathrm{CO}_{2}$ and $95 \%$ relative humidity. Following treatment, the medium was aspirated, and $100 \mu \mathrm{L}$ of culture medium containing $5 \mathrm{mg} / \mathrm{mL}$ of MTT dye was added to each well. Cells were incubated for $4 \mathrm{~h}$. The reaction mixture was carefully taken out and $150 \mu \mathrm{L}$ of DMSO was added to each well. The 96-well plates were shaken for $10 \mathrm{~min}$ and the absorbance was then recorded with dual waves at 570 and $650 \mathrm{~nm}$ by a 
microplate reader (Epoch, BioTek, Winooski, VT, USA). The cell viability was expressed as percentage of vehicle-treated controls.

\section{Measurement of Caspase-3 Activity}

Caspase- 3 activity was evaluated according to the manual of the Caspase-3 Activity Assay kit (Beyotime Shanghai, China). Briefly, the whole cell lysates (WCL) were added into 96-well plates and incubated with $2 \mathrm{mM}$ of caspase- 3 substrate (Ac-DEVD-pNA) at $37^{\circ} \mathrm{C}$ for $4 \mathrm{~h}$. The absorbance was measured at $405 \mathrm{~nm}$ using a microplate reader. The protein levels of the samples were measured by the Bradford protein assay (Beyotime, Shanghai, China). Relative caspase-3 activity was expressed as percentage of vehicle-treated controls.

\section{Membrane Blebbing, Neurite Length and Cell Body Area of PC12 Cells}

PC12 cells were seeded in 6-well plates at a density of $1 \times 10^{5}$ cells/mL, treated as mentioned above, and observed with a phase contrast microscope (Olympus Corporation, Tokyo, Japan). PC12 cells were considered blebbing when blebs extended and cell bodies contracted. The percent of blebbing cells was determined by counting total and blebbing cells under blinded conditions. Neurite length was measured from the tip of the neurite until the soma of the cell using the ImageJ software (National Institutes of Health, Bethesda, MD, USA). Cell body area was measured using the ImageJ software. Neurite length and cell body area were presented as percentage of controls.

\section{Transmission Electron Microscopy (TEM)}

Cell suspensions were centrifuged, resuspended in fixative in a Eppendorf tube, spun down again to form a pellet and stored overnight at $4^{\circ} \mathrm{C}$. Cells were then postfixed in $1 \%$ osmium tetroxide in $0.10 \mathrm{M}$ phosphate buffer, dehydrated in a graded series of ethanol (30,50, 70, 80, 90 and 100\%), infiltrated, and embedded in an "Epon-Araldite" mixture. Seventy-five nanometer sections were stained with uranyl acetate and bismuth subnitrite, and then examined in a transmission electron microscope (JEM-1010, JEOL Ltd, Tokyo, Japan) at $80 \mathrm{Kv}$ accelerating voltage.

\section{Immunofluorescence}

PC12 cells and neurons were washed with cold PBS, fixed in $4 \%$ paraformaldehyde, permeabilized with $0.1 \%$ Triton X-100 in PBS for $30 \mathrm{~min}$ at room temperature, blocked with 5\% BSA and incubated with rabbit anti-myosin IIA antibody at 1:200 dilution or rabbit anti-MAP2 antibody at 1:200 dilution overnight at $4^{\circ} \mathrm{C}$, followed by $1 \mathrm{~h}$ incubation with Alexa Fluor ${ }^{\circledR} 488$ donkey anti-rabbit antibody at 1:200 dilution at room temperature. Filamentous actin structures were stained with 1:200 dilution of Alexa Fluor ${ }^{\circledR} 568$ Phalloidin. Nuclei were visualized with DAPI. Fluorescent images were taken through laser excitation lines 405 , 488, $568 \mathrm{~nm}$ and Differential Interference Contrast (DIC) with confocal laser scanning microscope (LSM700, Zeiss, Germany). Cells were imaged with the same optical slice thickness in every channel using the Objective Plan-Apochromat $63 \times / 1.40$ Oil DIC M27. The resolution of images is $1024 \times 1024$ and the pinhole is set to one Airy unit. Images were obtained using the ZEN imaging software (Zeiss, Germany). Quantitative co-localization of myosin IIA or IIB with actin filaments was performed using the ImageJ software which can provide the Manders' coefficients for the overlap of the images. Its values range between 0 and 1.0. A value of 1 represents strong positive correlation and 0 indicates that there is no discernable correlation. Neurite length was quantified from neuronal cultures immunostained with MAP2 antibody. Neurite length was measured from the tip of the neurite until the soma of the neuron using the ImageJ software and was presented as percentage of control. All micrographs include a bar to indicate the scale.

\section{Western Blot}

Cells were washed twice with PBS, lysed in RIPA buffer containing complete protease inhibitor cocktail and centrifuged at $12,000 \mathrm{rpm}$ for $10 \mathrm{~min}$ at $4^{\circ} \mathrm{C}$. Protein concentrations were determined according to BCA protein assay. Equal amounts of proteins $(30 \mu \mathrm{g})$ were electrophoresed in 10\% SDS-PAGE gels, transferred onto polyvinylidene fluoride (PVDF) membranes (Millipore Corporation, Billerica, MA, USA). The targeting proteins were probed with antibodies against myosin IIA (1:1000), myosin IIB (1:1000), ROCK1 (1:300), ROCK2 (1:300), MLC (1:1000), P-MLC (Ser19, 1:1000), caspase-3 (1:1000), GAPDH $(1: 10,000)$ and appropriate HRP-conjugated secondary antibodies $(1: 10,000)$, followed by visualization with ECL and photographed using the Bio-Rad Gel Imaging System (BioRad, Hercules, CA, USA). Data analysis was done using ImageJ software measuring integrated density of bands after background subtraction.

\section{Immunoprecipitation}

The Protein A/G PLUS-Agarose was washed with RIPA buffer three times before mixing with antibody. Prior to immunoprecipitation, $2 \mu \mathrm{g}$ of purified antibodies against myosin IIA, actin filaments or normal IgG were mixed with $30 \mu \mathrm{L}$ of agarose solution, and incubated at $4^{\circ} \mathrm{C}$ overnight on a rocker table. The prepared antibody-agarose complex were added to $1 \mathrm{~mL}$ of WCL $(1 \mathrm{mg} / \mathrm{mL})$ and incubated with rocking for $4 \mathrm{~h}$ at $4^{\circ} \mathrm{C}$. The agarose-containing lysates were centrifuged and washed three times with RIPA buffer. Agarose-bound proteins were released by adding $2 \times$ SDS gel loading buffer and boiling for $5 \mathrm{~min}$. An equal volume of each sample was fractionated by $10 \%$ SDS-PAGE and blotted using specific antibodies.

\section{Statistical Analysis}

Data are presented as the means \pm SD of three independent experiments. Statistical analysis of the data was performed with Student's $t$ test for two group comparison or one-way analysis of variance (ANOVA) followed by Dunnett's post hoc test for multiple comparisons using GraphPad Prism 6.0 (GraphPad Software, La Jolla, CA, USA). $P<0.05$ was considered statistically significant. 


\section{RESULTS}

\section{$\mathrm{H}_{2} \mathrm{O}_{2}$ Induces Apoptosis and Membrane Blebbing in Neuronal Cells}

In the present study, we used highly differentiated PC12 cells and primary cultured rat cortical neurons stimulated by $\mathrm{H}_{2} \mathrm{O}_{2}$ as the in vitro neuronal oxidative stress models. Caspase- 3 activity significantly increased following $100 \mu \mathrm{M} \mathrm{H} \mathrm{H}_{2} \mathrm{O}_{2}$ treatment for $12 \mathrm{~h}$ in both PC12 cells and neurons (Figure 1A). The phase-contrast micrographs showed that normal PC12 cells had typical elongated and spreading morphology with extended neurites (Figure 1B, Control). Following $\mathrm{H}_{2} \mathrm{O}_{2}$ treatment, PC12 cells lost membrane extensions, detached from the culture support and shrunk to a rounded shape with obvious membrane blebbing (Figure 1B, $\mathrm{H}_{2} \mathrm{O}_{2}$ ). Transmission Electron Microscopy (TEM) was utilized to obtain fine-detailed photomicrographs of PC12 cells morphology. A typical apoptotic cell was observed with dramatic membrane blebs and chromatin condensation after $\mathrm{H}_{2} \mathrm{O}_{2}$ treatment (Figure 1C, $\mathrm{H}_{2} \mathrm{O}_{2}$ ). In contrast, control PC12 cells did not bleb and their nucleus remained intact (Figure 1C, Control). Consistently, similar results were also observed in neurons (Figure 1D).

\section{Myosin IIA-actin Interaction Mediates $\mathrm{H}_{2} \mathrm{O}_{2}$-induced Neuronal Apoptosis}

Previous studies have shown that morphological changes in apoptotic cells are dependent on actomyosin cytoskeleton remodeling (Wickman et al., 2013; Turney et al., 2016). To understand which myosin II isoform regulates neuronal apoptosis, we examined the relocalization of the two myosin II isoforms and actin filaments in response to $\mathrm{H}_{2} \mathrm{O}_{2}$. In normal PC12 cells and neurons, myosin IIA and IIB have distinct cellular localization pattern, while actin showed a similar pronounced peripheral localization. Myosin IIA was distributed throughout the cytoplasm and neuritis (Figures 2A,C), whereas myosin IIB tended to be broadly peripheral and associated more with actin comparing to myosin IIA (Figures 3A,C). $\mathrm{H}_{2} \mathrm{O}_{2}$ exposure induced dramatic changes of cell morphology, as well as the reorganization of myosin IIA, IIB and F-actin. Myosin IIA and F-actin accumulated to form a dense spherical network. Myosin IIA had a stronger association with actin filaments under oxidative stress than normal conditions (Figures 2B,D). Quantitive analysis by Manders' overlap coefficients (Bolte and Cordelières, 2006) showed that myosin IIA and actin filaments exhibited statistically significant co-localization upon $\mathrm{H}_{2} \mathrm{O}_{2}$ treatment in both PC12 cells (Figure 2E) and neurons (Figure 2F). Co-immunoprecipitation analysis also confirmed the increased interaction of myosin IIA and F-actin induced by oxidative stress (Figures 2G,H).

$\mathrm{H}_{2} \mathrm{O}_{2}$ treatment didn't significantly increase the interaction of myosin IIB with actin filaments in apoptotic PC12 cells (Figures 3B,E). Co-immunoprecipitation analysis also showed that the interaction between myosin IIB and actin didn't change in $\mathrm{PC} 12$ cells induced by $\mathrm{H}_{2} \mathrm{O}_{2}$ (Figure 3G). While

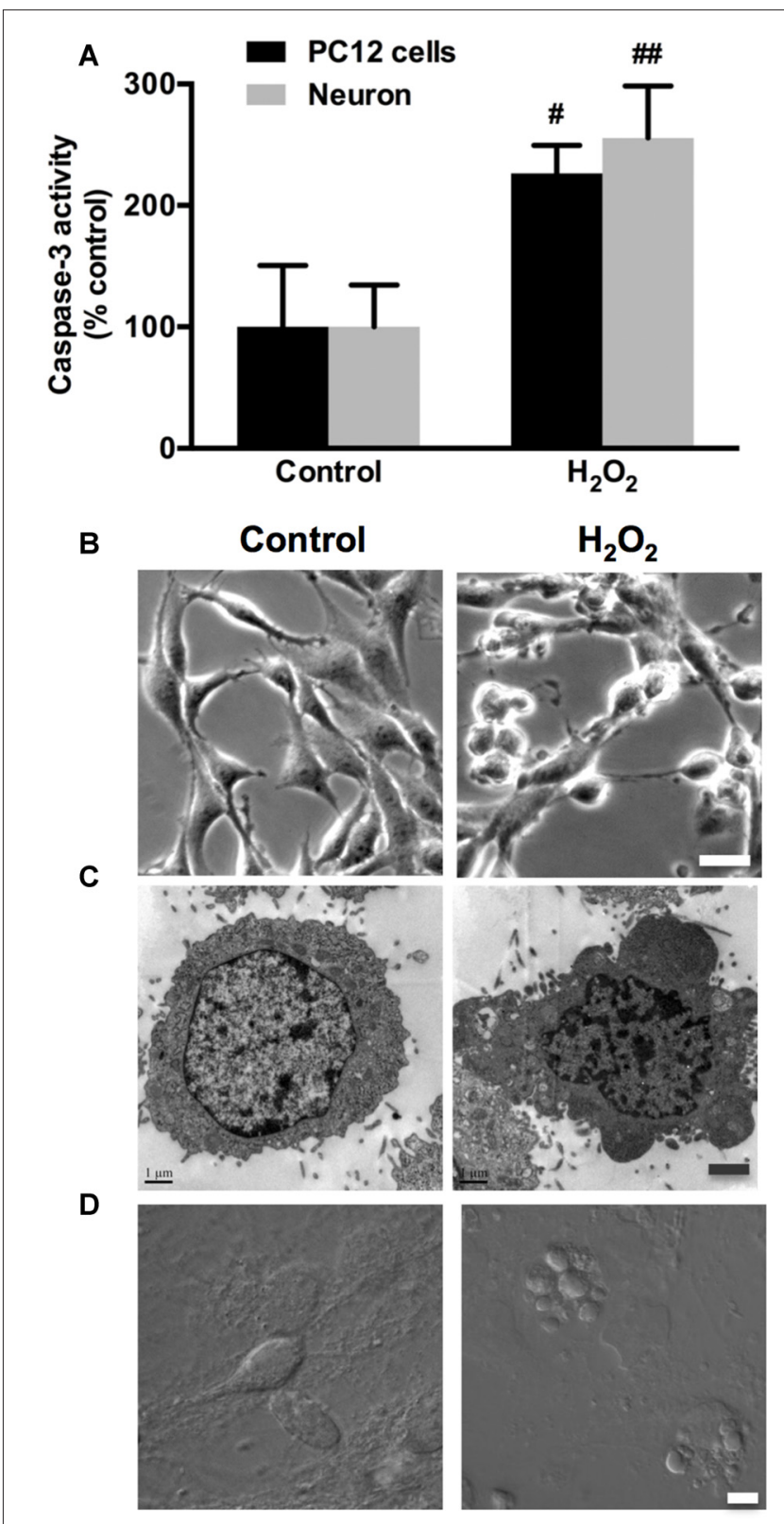

FIGURE 1 | Hydrogen peroxide $\left(\mathrm{H}_{2} \mathrm{O}_{2}\right)$ induces apoptosis and membrane blebbing in PC12 cells and neurons. (A) PC12 cells and neurons were exposed to $100 \mu \mathrm{M} \mathrm{H}_{2} \mathrm{O}_{2}$ for $12 \mathrm{~h}$. Caspase- 3 activity was evaluated in PC12 cells and neurons. (B) PC12 cells morphology using phase-contrast microscopy. Bar, $10 \mu \mathrm{m}$. (C) Transmission electron microscopy (TEM) of PC12 cells. Bar, 1 Mm. (D) Neurons were imaged through differential interference contrast (DIC) using confocal laser scanning microscope (LSM). Bar, $5 \mu \mathrm{m}$. Results were expressed as mean \pm SD from three independent experiments ( $P<0.05$ vs. control, ${ }^{\# \# ~} P<0.01$ vs. control).

in neurons, myosin IIB staining became dimmer and punctate with decreased co-localization with actin under $\mathrm{H}_{2} \mathrm{O}_{2}$ exposure (Figures 3D,F). Western blot analysis showed that $\mathrm{H}_{2} \mathrm{O}_{2}$ treatment significantly decreased myosin IIB expression in neurons (Figure $3 \mathbf{H}$ ), while had no effect on the protein level of myosin IIA (Supplementary Figure S1A). $\mathrm{H}_{2} \mathrm{O}_{2}$ also 


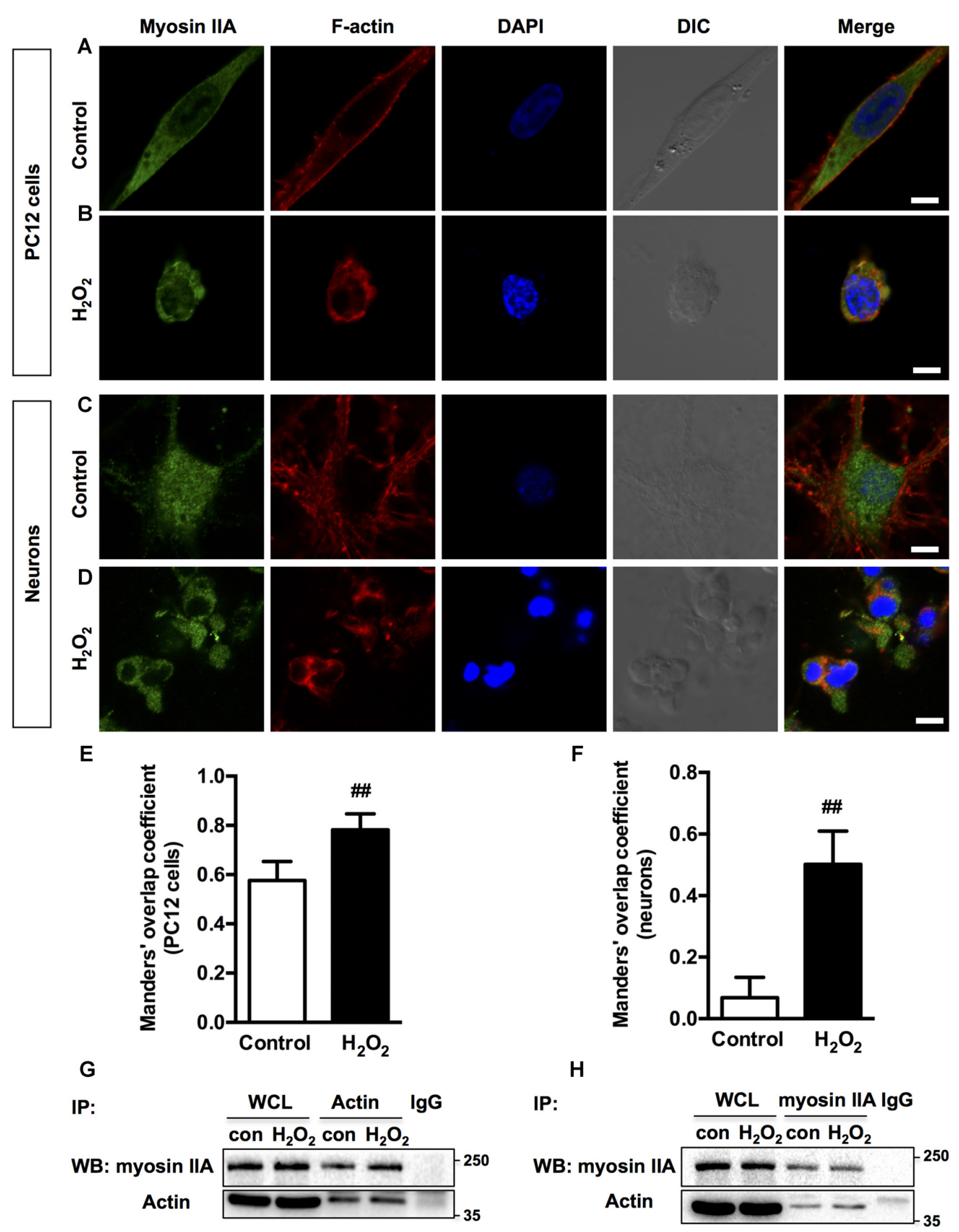

FIGURE 2 | Localization of myosin IIA and F-actin in PC12 cells or neurons upon $\mathbf{H}_{2} \mathbf{O}_{2}$ treatment. $\mathrm{PC} 12$ cells untreated (A) or treated (B) with $100 \mu \mathrm{M}$ $\mathrm{H}_{2} \mathrm{O}_{2}$ for $12 \mathrm{~h}$ were stained with myosin IIA (green), F-actin (red) and DAPI (blue). Neurons untreated (C) or treated (D) with $100 \mu \mathrm{M} \mathrm{H} \mathrm{H}_{2} \mathrm{O}_{2}$ for $12 \mathrm{~h}$ were stained with myosin IIA (green), F-actin (red) and DAPI (blue). Images were obtained by confocal microscopy. Bar, $5 \mu \mathrm{m}$. The co-localization of myosin IIA with F-actin in PC12 cells $(\mathbf{E})$ or neurons $(\mathbf{F})$ was evaluated on the basis of Manders' overlap coefficients. Results were expressed as mean \pm SD (\#\# $P<0.01$ vs. control). Experiments were performed three times independently. Protein interaction between myosin IIA and actin was determined by co-immunoprecipitation. Following treatment, cell lysates were immunoprecipitated with anti-actin antibody (G) or anti-non-muscle myosin IIA antibody (H). Isotype-matched (IgG) served as negative control (NC). Each precipitated sample was detected for the presence of myosin IIA and actin by immunoblot analysis using specific antibodies. Whole cell lysates (WCL) prior to the immunoprecipitation served as input controls. 


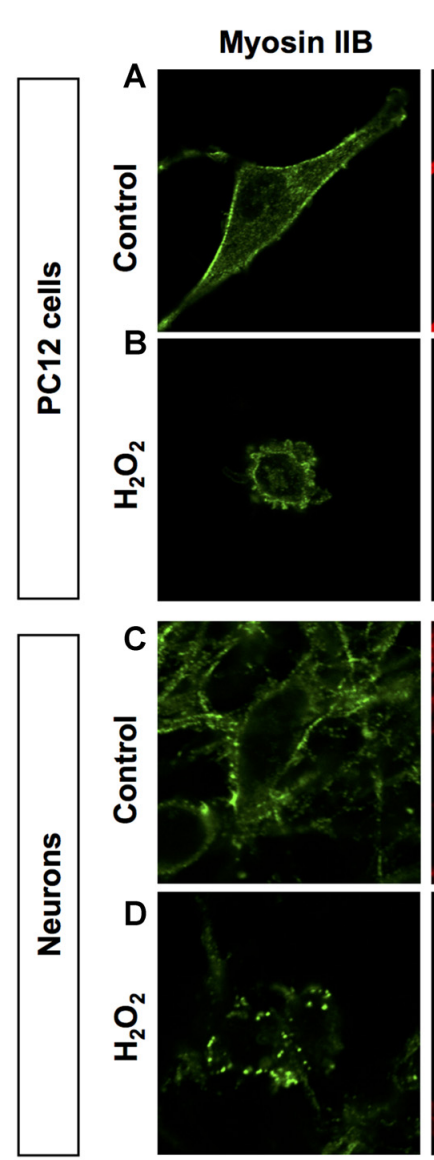

E

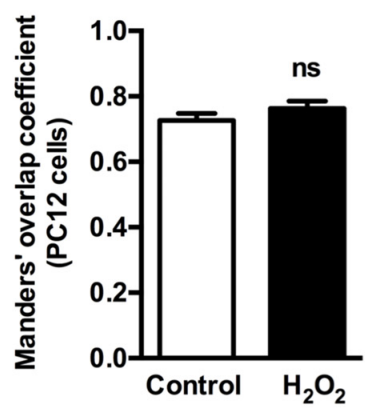

F-actin
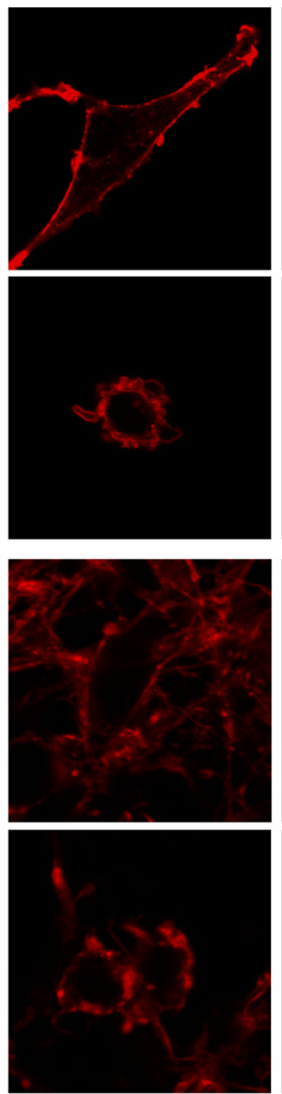

$\mathbf{F}$

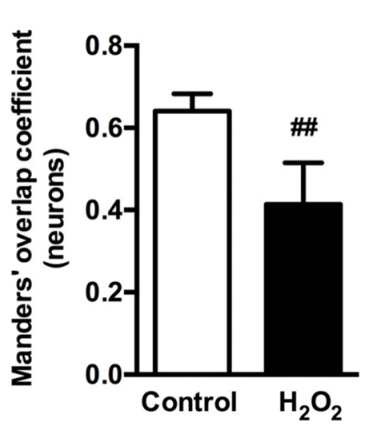

DAPI
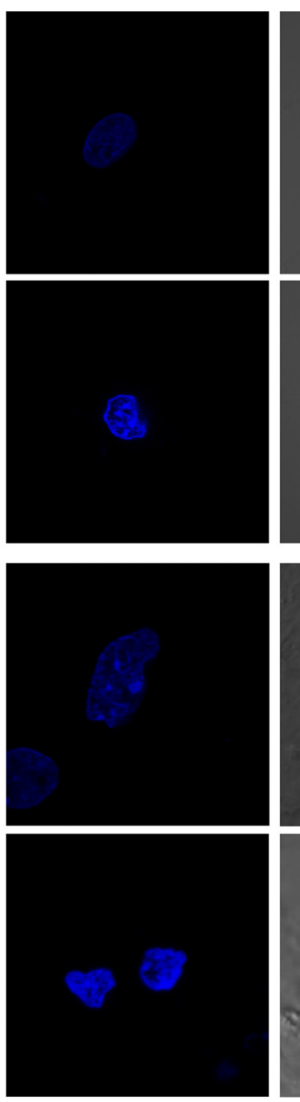

H
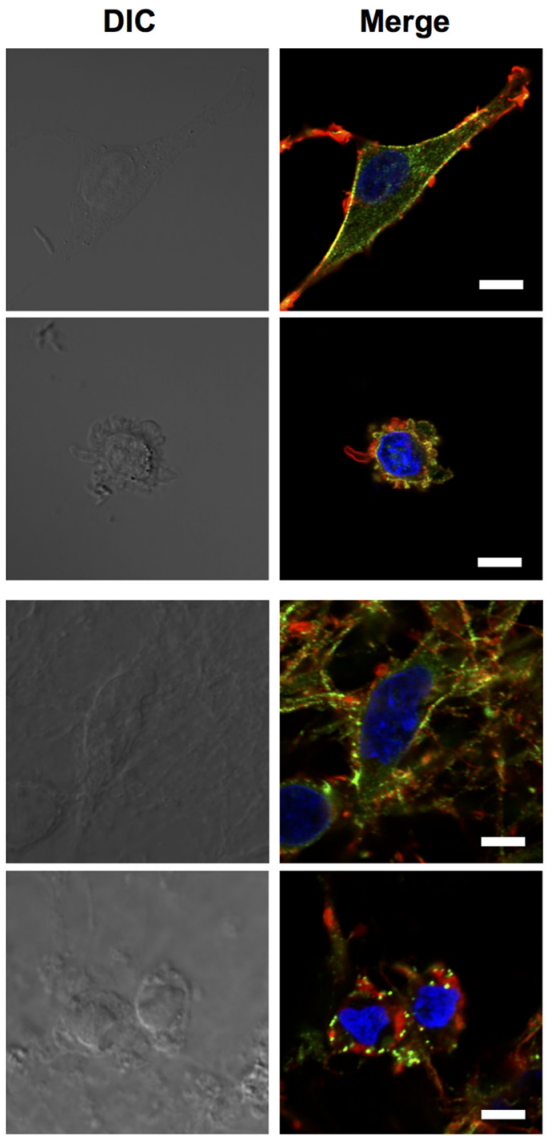

H
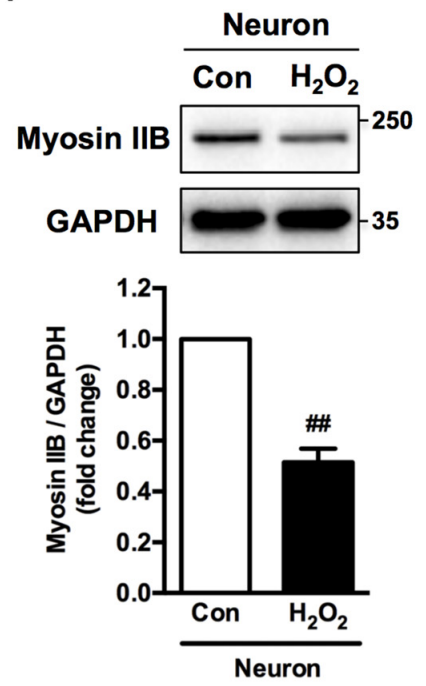

FIGURE 3 | Localization of myosin IIB and F-actin in PC12 cells or neurons upon $\mathbf{H}_{\mathbf{2}} \mathbf{O}_{\mathbf{2}}$ treatment. $\mathrm{PC} 12$ cells untreated (A) or treated (B) with $100 \mu \mathrm{M}$ $\mathrm{H}_{2} \mathrm{O}_{2}$ for $12 \mathrm{~h}$ were stained with myosin IIB (green), F-actin (red) and DAPI (blue). Neurons untreated (C) or treated (D) with $100 \mu \mathrm{M} \mathrm{H} \mathrm{O}_{2}$ for $12 \mathrm{~h}$ were stained with myosin IIB (green), F-actin (red) and DAPI (blue). Images were obtained by confocal microscopy. Bar, $5 \mu \mathrm{m}$. The co-localization of myosin IIB with F-actin in PC12 cells (E) or neurons (F) was evaluated on the basis of Manders' overlap coefficients. Results were expressed as mean \pm SD (\#\# $P<0.01$ vs. control).

(G) Protein interaction between myosin IIB and F-actin was determined by co-immunoprecipitation. Following treatment, cell lysates were immunoprecipitated with anti-actin antibody and isotype-matched IgG control. Each precipitated sample was detected for the presence of myosin IIB and actin by immunoblot analysis using specific antibodies. WCL prior to the immunoprecipitation served as input controls. $(\mathbf{H})$ Expression of $\mathrm{Myosin}_{\mathrm{NB}}$ in neurons treated or untreated with $\mathrm{H}_{2} \mathrm{O}_{2}$ was evaluated by immunoblot analysis. 
didn't change the level of myosin IIA of IIB in PC12 cells (Supplementary Figure S1B). We then examined the expression levels of myosin II isoforms in PC12 cells and neurons. There was higher myosin IIA expression in PC12 cells and similar myosin IIB levels in both kinds of cells (Supplementary Figure S1C).

Although the co-localization of myosin IIB with actin filaments was more striking under normal conditions, myosin IIA tended to bind with more actin filaments under $\mathrm{H}_{2} \mathrm{O}_{2}$ treatment. The increased interaction between myosin IIA and actin suggested that actin polymerization might also play a role during $\mathrm{H}_{2} \mathrm{O}_{2}$ exposure. Therefore, we applied actin filament assembly inhibitor, cytochalasin D before $\mathrm{H}_{2} \mathrm{O}_{2}$ injury. Cytochalasin D inhibited PC12 cells membrane blebbing and caspase- 3 activation induced by $\mathrm{H}_{2} \mathrm{O}_{2}$ (Supplementary Figure S2).

\section{Distinct Effects of Myosin IIA or IIB Knockdown on $\mathrm{H}_{2} \mathrm{O}_{2}$-induced PC12 Cells Apoptosis}

To investigate the specific roles of myosin II isoforms in neuronal apoptosis, we transfected PC12 cells with siRNAs targeting at myosin IIA or IIB. Transfection of PC12 cells with \#1 Myh9 siRNA (siMyh9) or 1\# Myh10 siRNA (siMyh10) led to attenuated expression of myosin IIA or IIB to $20 \%-30 \%$ of the control values, without affecting the levels of the other isoforms (Supplementary Figure S3). Knockdown of myosin IIA caused remarkable expansion in cell body area and increased neurite length. In contrast, depletion of myosin IIB led to a raised and rounded cell body with dramatic decreases in its size and neurite length, which suggests opposing roles of myosin IIA and IIB in regulating the morphology of PC12 cells (Figure 4D, Control). Knockdown of myosin IIA protected PC12 cells from $\mathrm{H}_{2} \mathrm{O}_{2}$-induced membrane blebbing, cell contraction and neurite retraction, compared with PC12 cells transfected with NC siRNA. In contrast, knockdown of myosin IIB further increased membrane blebbing, cellular contraction and neurite retraction under $\mathrm{H}_{2} \mathrm{O}_{2}$ exposure (Figures 4A-D, $\mathrm{H}_{2} \mathrm{O}_{2}$ ).

MTT assay showed that myosin IIA knockdown didn't change, while myosin IIB knockdown increased cell viability in PC12 cells. Under $\mathrm{H}_{2} \mathrm{O}_{2}$ treatment, both myosin IIA and IIB knockdown increased cell viability compared with control (Figure 4E). This might result from the increased cell number following myosin IIB knockdown (Figure 4F). To exclude the effects of cell number, we then subtracted $\mathrm{H}_{2} \mathrm{O}_{2}$-induced cell viability from form untreated cells, which represents the decreased cell viability. There was a more severe reduction in cell viability of myosin IIB knockdown cells than that of control or myosin IIA knockdown cells (Figure 4G). Consistently, caspase-3 activity assay showed that myosin IIA depletion inhibited $\mathrm{H}_{2} \mathrm{O}_{2}$-induced caspase- 3 activation, while myosin IIB knockdown further increased $\mathrm{H}_{2} \mathrm{O}_{2}$-induced caspase-3 activation in PC12 cells (Figure 4H). Our data indicated a critical role for myosin IIA in the progressive apoptosis of neuronal cells induced by $\mathrm{H}_{2} \mathrm{O}_{2}$.

\section{Myosin IIA Knockout by CRISPR/Cas9 Attenuates $\mathrm{H}_{2} \mathrm{O}_{2}$-induced PC12 Cells Apoptosis}

To further confirm the role of myosin IIA in regulating $\mathrm{H}_{2} \mathrm{O}_{2}$-induced neuronal apoptosis, we knocked out $M y h 9$ gene in PC12 cells with the CRISPR/Cas9 system. Western blot analysis revealed that colony \#1, \#2 and \#3 were completely depleted of myosin IIA protein compared with wild-type (WT) cells, without affecting the level of myosin IIB (Figure 5A). Consistently, Myh9 knockout enlarged cell body area under normal conditions, and inhibited cell contraction and membrane blebbing upon $\mathrm{H}_{2} \mathrm{O}_{2}$ exposure (Figure 5B). Myh 9 knockout also increased cell viability and decreased caspase- 3 activation after $\mathrm{H}_{2} \mathrm{O}_{2}$ treatment compared with WT cells (Figures 5C,D). Our observation demonstrates the critical and specific role of myosin IIA in regulating $\mathrm{H}_{2} \mathrm{O}_{2}$-induced PC12 cells apoptosis.

\section{$\mathrm{H}_{2} \mathrm{O}_{2}$ Induces Caspase-3/ROCK1/MLC Pathway Activation in Neuronal Cells}

ROCK1 contributes to actomyosin contractility and causes cellular blebs to protrude through MLC phosphorylation (P-MLC). Caspase-3 has also been reported to be important in such morphological changes (Sebbagh et al., 2001). Time-course study revealed that $\mathrm{H}_{2} \mathrm{O}_{2}$ increased the cleavage of caspase- 3 as early as $3 \mathrm{~h}$ after $\mathrm{H}_{2} \mathrm{O}_{2}$ exposure (Figure 6A). A small cleavage fragment of $\mathrm{Mr} 30 \mathrm{~K}$ ROCK1 was detectable using the C-19 antibody after $6 \mathrm{~h}$ of $\mathrm{H}_{2} \mathrm{O}_{2}$ treatment, while the abundance of the full-length $\mathrm{Mr} 160 \mathrm{~K}$ protein decreased reciprocally (Figure 6B). In contrast, no such fragment or reduction of the $\mathrm{Mr} 160 \mathrm{~K}$ band was observed using the specific anti-ROCK2 antibody (C20; Figure 6C). MLC phosphorylation culminated after $12 \mathrm{~h}$ of $\mathrm{H}_{2} \mathrm{O}_{2}$ incubation and decreased thereafter (Figure 6D). Caspase-3, ROCK1, ROCK2 and MLC phosphorylation had similar changes in neurons upon $\mathrm{H}_{2} \mathrm{O}_{2}$ treatment for $12 \mathrm{~h}$ (Supplementary Figure S4). Together, there was a sequential activation of caspase 3 , ROCK1 and MLC during $\mathrm{H}_{2} \mathrm{O}_{2}$ exposure in neuronal cells.

\section{Caspase, ROCK or Myosin II Inhibition Attenuates $\mathrm{H}_{2} \mathrm{O}_{2}$-induced Neuronal Apoptosis and Membrane Blebbing}

We further investigated whether the observed association among caspase, ROCK or myosin II during apoptosis could be blocked by related chemical inhibitors. On the basis of cell viability, $1 \mu \mathrm{M}$ blebbistatin was applied to reduce any possible toxic and nonspecific effects. Pretreatment with $1 \mu \mathrm{M}$ blebbistatin (myosin II ATPase inhibitor), $10 \mu \mathrm{M}$ Y27632 (ROCK inhibitor) or $10 \mu \mathrm{M} \mathrm{z}$-VAD-fmk (caspase inhibitor) increased cell viability (Figure 7A), decreased caspase-3 activity (Figure 7B), inhibited membrane blebbing and increased neurite length (Figure 7C) after $\mathrm{H}_{2} \mathrm{O}_{2}$ exposure in both PC12 cells and neurons. Consistent with phase-contrast micrographs, TEM results indicated that pretreatment with blebbistatin, Y27632 and z-VAD-fmk blocked membrane blebbing and nucleus condensation induced by $\mathrm{H}_{2} \mathrm{O}_{2}$ in PC12 cells (Figure 7D). Statistical analysis showed 
A

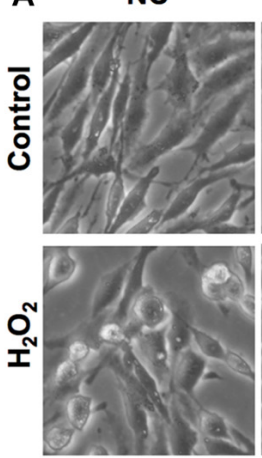

siMyh9
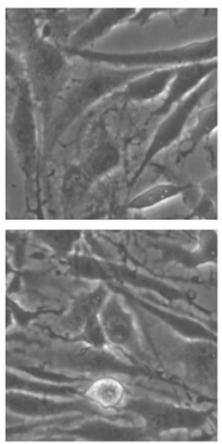

C

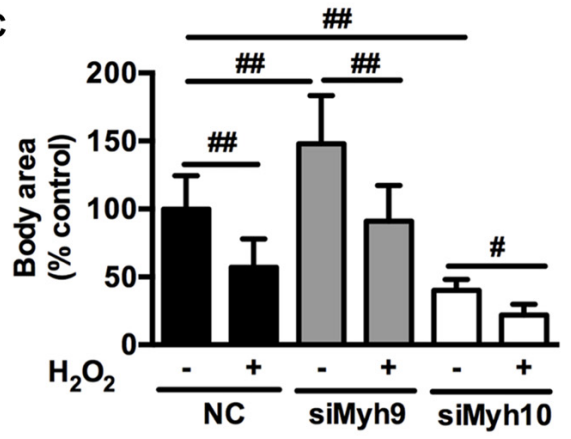

E

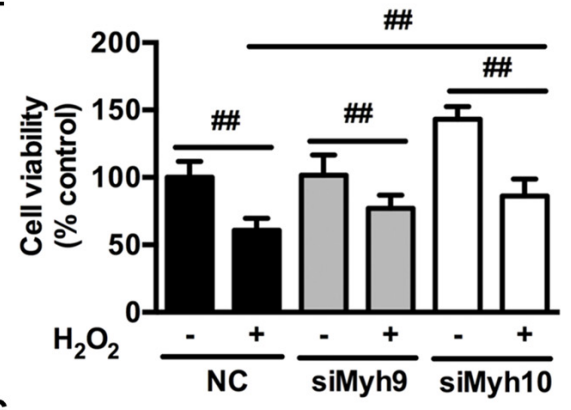

$\mathbf{G}$

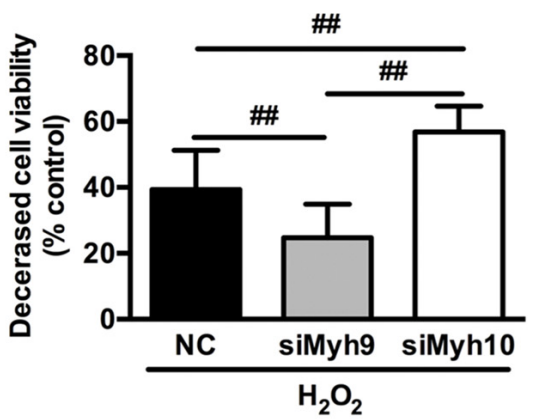

B
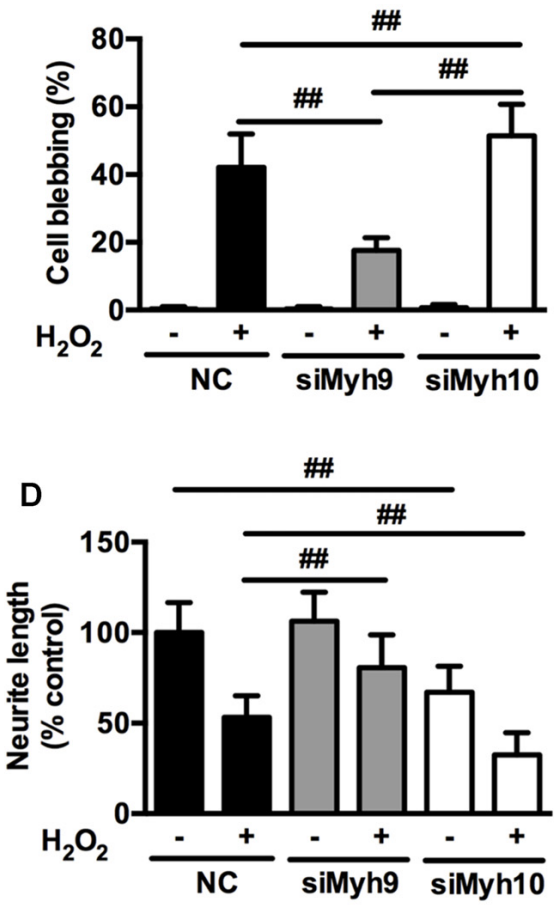

$\mathbf{F}$

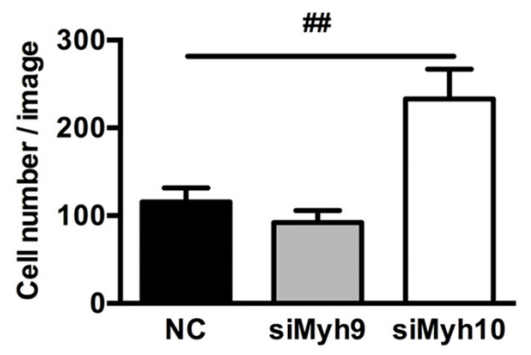

H

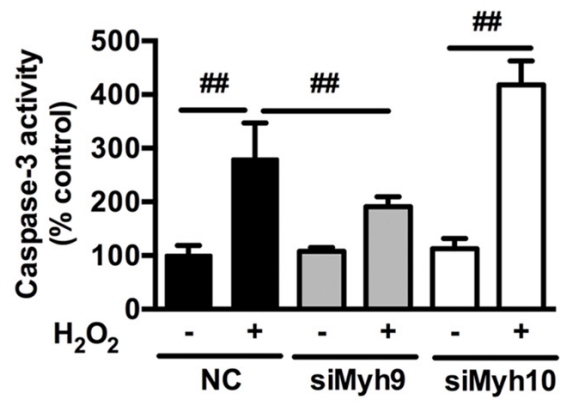

FIGURE 4 | Distinct effects of myosin IIA or IIB knockdown on $\mathrm{H}_{2} \mathrm{O}_{2}$-induced morphological changes and apoptosis in PC12 cells. PC12 cells were transfected with siRNAs against myosin IIA (\#1 siMyh9), myosin IIB (\#1 siMyh10), or NC sequence as described in experimental procedures. (A) Representative phase-contrast micrographs of transfected PC12 cells treated or untreated with $\mathrm{H}_{2} \mathrm{O}_{2}$. Bar, $10 \mu \mathrm{m}$. (B) PC12 cells with membrane blebs were counted and the percentage of these cells with respect to the total cell population was calculated. Body area (C) and neurite length (D) was measured using the ImageJ software. The results were represented as percentage of control. (E) Viability of transfected cells was evaluated by 3-(4,5-dimethylthiazol-2-yl)-2,5-diphenyl tetrazolium bromide (MTT) assay. (F) The number of PC12 cells transfected with siRNAs targeting at myosin IIA or IIB was counted in the bright-field images. (G) Decreased cell viability was calculated by subtracting viability of $\mathrm{H}_{2} \mathrm{O}_{2}$-treated cells from control cells. $\mathbf{( H )}$ Caspase-3 activity was measured by caspase-3 activity assay kit. Values were represented as mean \pm SD from three independent experiments $(\# P<0.05, \# \#<0.01)$. 
A

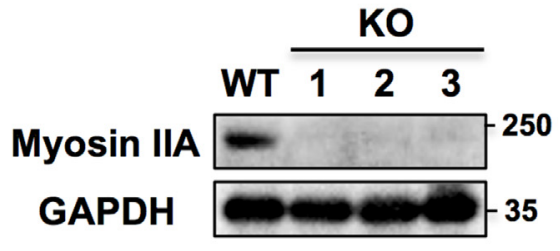

B

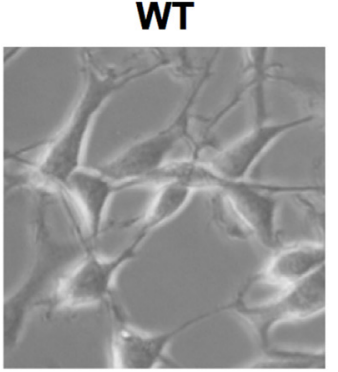

C

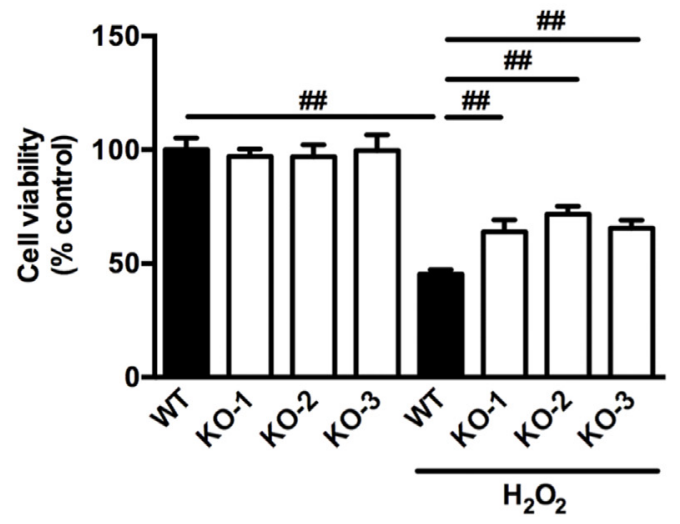

KO
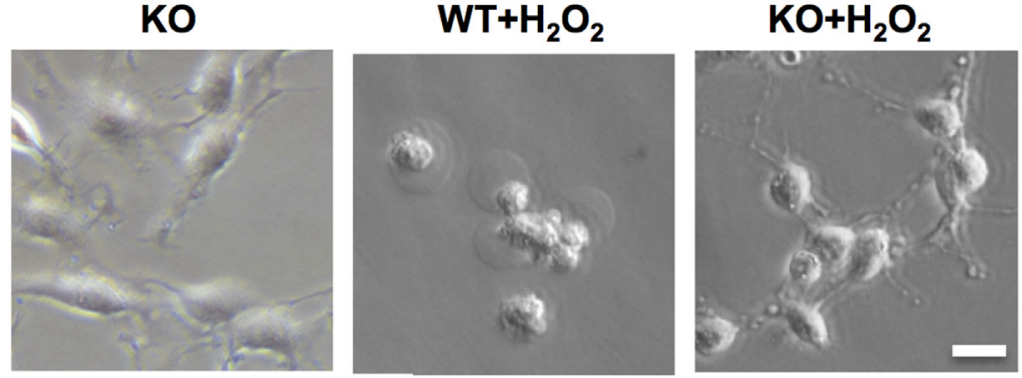

D

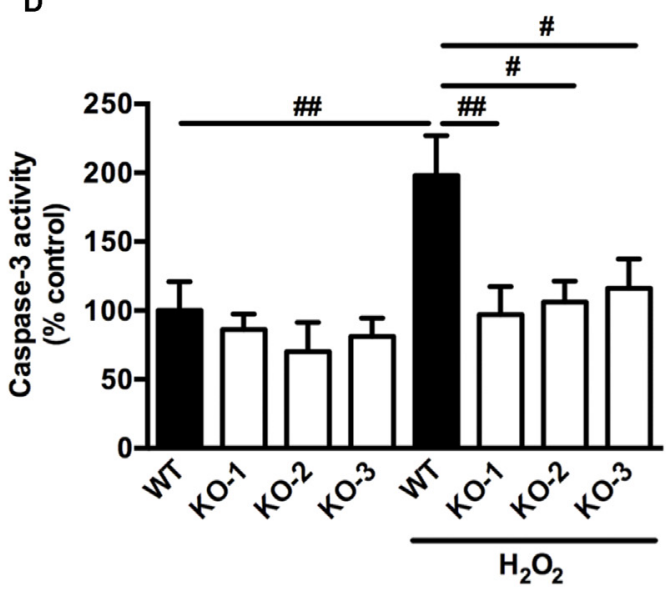

FIGURE 5 | Myosin IIA knockout by clustered regularly interspaced short palindromic repeats/CRISPR-associated protein-9 nuclease (CRISPR/Cas9) attenuates $\mathbf{H}_{\mathbf{2}} \mathbf{O}_{\mathbf{2}}$-induced morphological changes and apoptosis in PC12 cells. (A) Stable Myh9 knockout PC12 cells were established by CRISPR/Cas9. Cell lysates from single cell colonies \#1, \#2, \#3 and wild-type (WT) cells were analyzed by western blotting using myosin IIA, myosin IIB and GAPDH antibodies.

(B) The WT and Myh9 knockout PC12 cells were untreated or treated with $100 \mu \mathrm{M} \mathrm{H}_{2} \mathrm{O}_{2}$ for $12 \mathrm{~h}$. Cells were imaged using phase-contrast microscopy. Bar, $10 \mu \mathrm{m}$. (C) Viability of WT and Myh9 knockout PC12 cells treated or untreated with $\mathrm{H}_{2} \mathrm{O}_{2}$ was evaluated by MTT assay. (D) Caspase-3 activity was measured by caspase-3 activity assay kit. Values were represented as mean \pm SD from three independent experiments $\left({ }^{\#} P<0.05,{ }^{\# \#} P<0.01\right)$.

that these inhibitors significantly decreased percentage of blebbing cells and increased neurite length after $\mathrm{H}_{2} \mathrm{O}_{2}$ treatment (Figures 7E,F). MAP2, a cytoskeletal phosphoprotein, is reported to degrade after ischemia and other injuries. Loss of MAP2 immunoreactivity is a marker of neuronal damage (Shelton et al., 2015). Blebbistatin, Y27632 and z-VAD-fmk rescued the decrease of MAP2 fluorescence and neurite length in neurons under $\mathrm{H}_{2} \mathrm{O}_{2}$ induction (Figure 8).

Caspase-3 inhibitor, $z$-DEVD-fmk inhibited $\mathrm{H}_{2} \mathrm{O}_{2}$-induced membrane blebbing and caspase-3 activity (Supplementary Figure S5), which indicated that caspase-3 activation played a major role in $\mathrm{H}_{2} \mathrm{O}_{2}$-induced apoptosis. MLC phosphorylation may occur via ROCK or MLCK. To address the role of MLCK in $\mathrm{H}_{2} \mathrm{O}_{2}$-induced membrane blebbing, cells were incubated with MLCK inhibitor ML-7 prior to $\mathrm{H}_{2} \mathrm{O}_{2}$ treatment. ML-7 failed to inhibit membrane blebbing and caspase 3 activity (Supplementary Figure S5), which indicated that MLCK was probably not involved in $\mathrm{H}_{2} \mathrm{O}_{2}$-induced neuronal apoptosis.

\section{Caspase, ROCK or Myosin II Inhibition Attenuates $\mathrm{H}_{2} \mathrm{O}_{2}$-induced Caspase-3/ROCK1/MLC/Myosin IIA-actin Cascade Pathway Activation}

We next investigated if blebbistatin, Y27632 or z-VAD-fmk attenuated myosin IIA-actin interaction induced by $\mathrm{H}_{2} \mathrm{O}_{2}$. In the presence of blebbistatin, Y27632 or z-VAD-fmk, the inhibition of membrane blebbing was associated with 

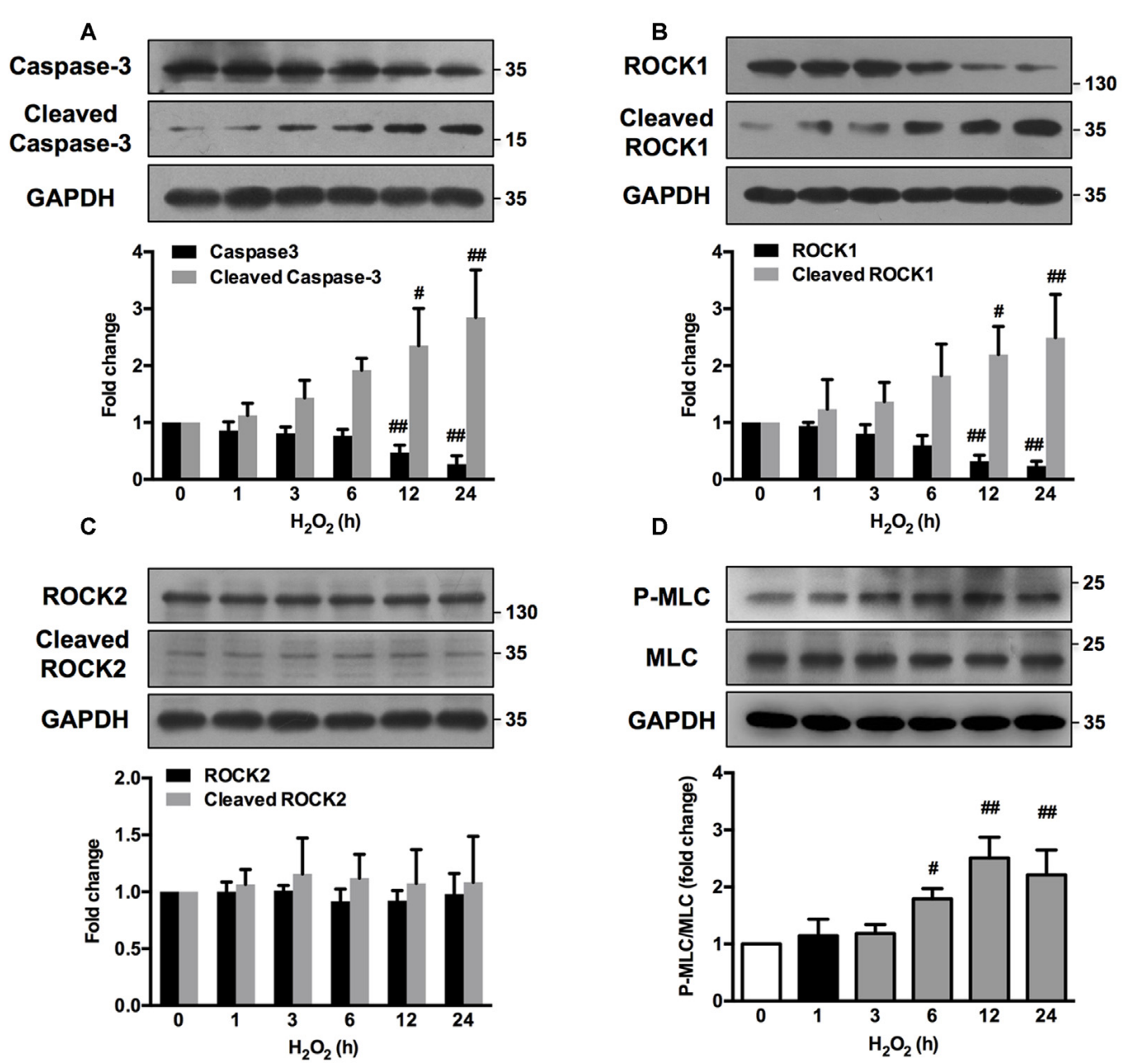

FIGURE $6 \mid \mathrm{H}_{2} \mathrm{O}_{2}$ activates caspase-3/Rho-associated kinase (ROCK1)/myosin light chain (MLC) pathway in PC12 cells. PC12 cells were incubated with $100 \mu \mathrm{M} \mathrm{H}_{2} \mathrm{O}_{2}$ for increasing periods of time. Total cell lysates were prepared, subjected to Western blot analysis with antibodies against caspase-3, cleaved caspase-3 (A), ROCK1, cleaved ROCK1 (B), ROCK2, cleaved ROCK2 (C), MLC and P-MLC (Ser-19) (D), and incubated with anti-GAPDH as loading control. Results were expressed as mean \pm SD from three independent experiments $\left({ }^{\#} P<0.05,{ }^{\#} P<0.01\right.$ vs. control).

a reversion of the cell morphology and myosin IIA-actin reorganization toward control cells, exhibiting decreased myosin IIA-actin interaction (Figures 9A-F). The statistical analysis also revealed that blebbistatin, Y27632 or z-VAD-fmk significantly inhibited the co-localization between myosin IIA and actin filaments (Figure 9G). Similar results were also observed in neurons (Figure 10). These findings demonstrated that caspase3/ROCK1/MLC activation plays a key role in triggering the downstream myosin IIA-actin hyperactivation upon $\mathrm{H}_{2} \mathrm{O}_{2}$ exposure.

Interestingly, Western blot analysis showed that myosin IIA-actin interaction inhibition by blebbistatin attenuated $\mathrm{H}_{2} \mathrm{O}_{2}$ induced activation of caspase-3, ROCK1 and MLC, indicating that myosin IIA might reversely influence caspase-3, ROCK1 and MLC activity. Y27632 and z-VAD-fmk also attenuated $\mathrm{H}_{2} \mathrm{O}_{2}$-induced cleaved caspase-3, cleaved ROCK1 and MLC phosphorylation (Figure 11). These results demonstrated that
$\mathrm{H}_{2} \mathrm{O}_{2}$-induced caspase-3/ROCK1/MLC activation and myosin IIA-actin interaction cascade might form a positive feedback pathway in $\mathrm{H}_{2} \mathrm{O}_{2}$-induced neuronal apoptosis (Figure 12). The original uncropped images of western blots are shown in Supplementary Figures S6-S9.

\section{DISCUSSION}

\section{Interaction of Myosin IIA or IIB with Actin Filaments in Neuronal Cells}

The interaction of myosin II with actin filaments in generating forces during the execution phase of apoptosis has been well documented (Ndozangue-Touriguine et al., 2008). However, little is known about the specific functions of myosin II isoforms in neuronal apoptosis. Normally, myosin IIA was dispersed throughout the cytoplasm, in contrast to the pronounced peripheral localization of myosin IIB and F-actin, which 
A

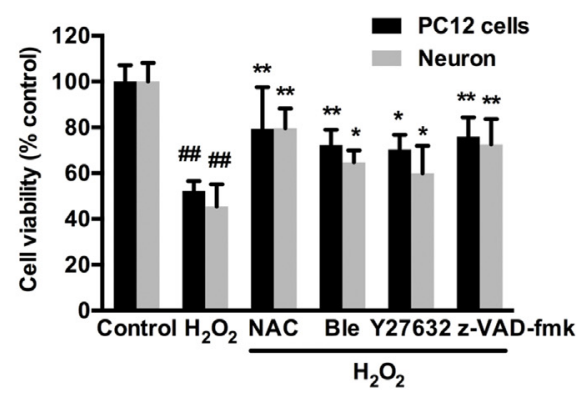

B
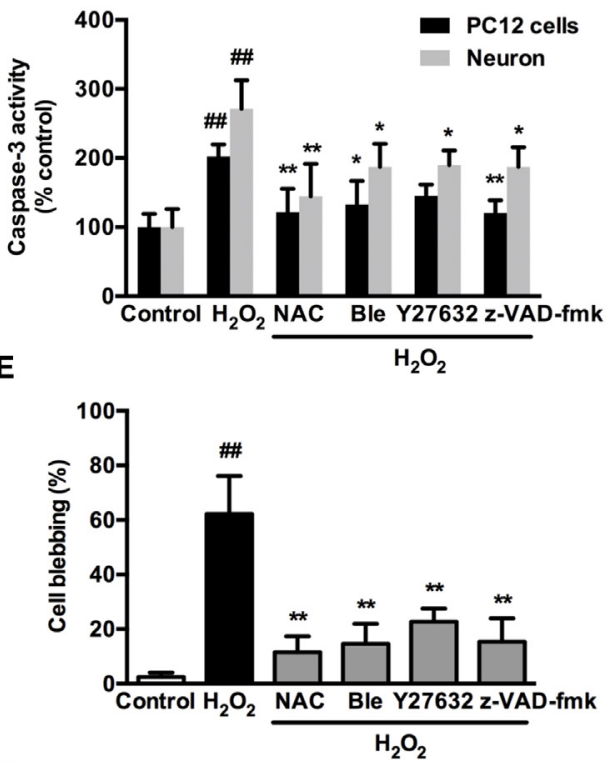

$\mathbf{F}$

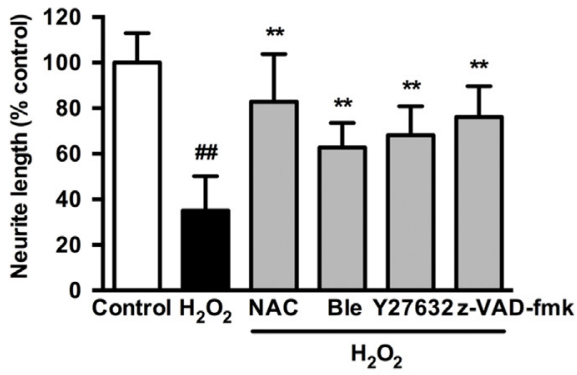

C
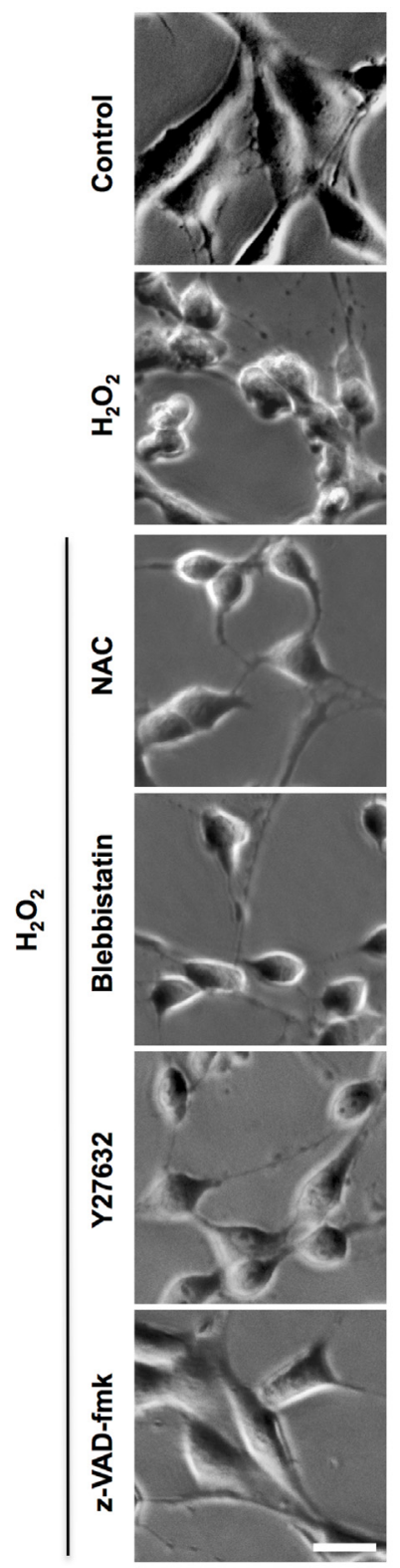

D
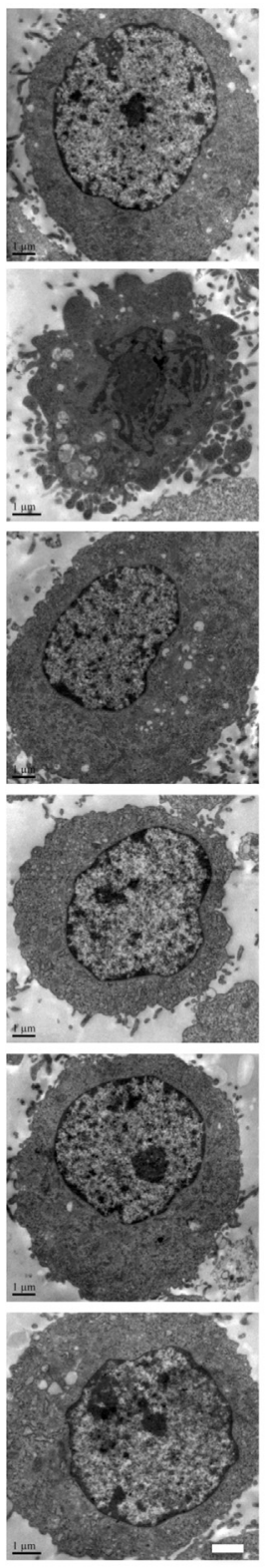

FIGURE 7 | Caspase, ROCK or myosin II inhibition attenuates $\mathrm{H}_{2} \mathrm{O}_{2}$-induced neuronal apoptosis, membrane blebbing and neurite retraction. $\mathrm{PC} 12$ cells or neurons were untreated or pretreated with $1 \mu \mathrm{M}$ blebbistatin, $10 \mu \mathrm{M}$ Y27632 or $10 \mu \mathrm{M}$ z-VAD-fmk for $1 \mathrm{~h}$ prior to $100 \mu \mathrm{M} \mathrm{H} \mathrm{O}_{2}$ treatment for $12 \mathrm{~h}$. $\mathrm{N}$-acetyl-L-cysteine (NAC; $500 \mu \mathrm{M}$ ) served as positive control. (A) Viability of PC12 cells and neurons was evaluated by MTT assay. (B) Caspase-3 activity of PC12 cells and neurons was determined by caspase-3 activity assay kit. (C) Representative phase-contrast micrographs of PC12 cells. Bar, $10 \mu \mathrm{m}$. (D) TEM of treated PC12 cells. Bar, $1 \mu \mathrm{m}$. (E) PC12 cells with membrane blebs were counted and the percentage of these cells with respect to the total cell population was calculated. (F) Neurite length was measured using the ImageJ software. The results were represented by the percentage of neurite length compared to control. Results were expressed as mean $\pm \mathrm{SD}$ from three independent experiments (\#\# $P<0.01$ vs. control, ${ }^{*} P<0.05$ vs. $\mathrm{H}_{2} \mathrm{O}_{2}$-treated cells, ${ }^{* *} P<0.01$ vs. $\mathrm{H}_{2} \mathrm{O}_{2}$-treated cells)

indicated that myosin IIA was better suited for large scale contractile processes than myosin IIB (Wylie and Chantler, 2003). Accordingly, the interaction of myosin IIA and actin increased upon $\mathrm{H}_{2} \mathrm{O}_{2}$ treatment, whereas myosin IIB and actin interaction showed no obvious change in PC12 cells and decreased in neurons as myosin IIB protein degraded. Why was myosin IIA retained but IIB lost after $\mathrm{H}_{2} \mathrm{O}_{2}$ exposure in neurons? On one hand, our results have demonstrated the requirement of actin filaments for cell contraction and membrane bleb formation during neuronal apoptosis. On the other hand, the 
A

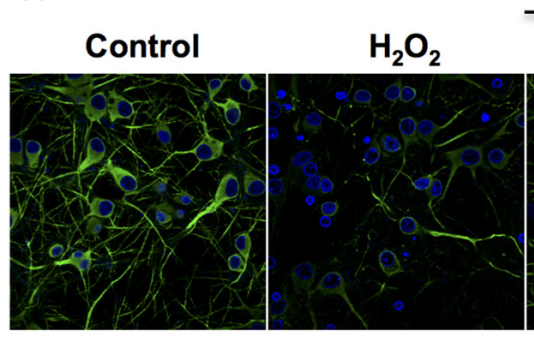

B

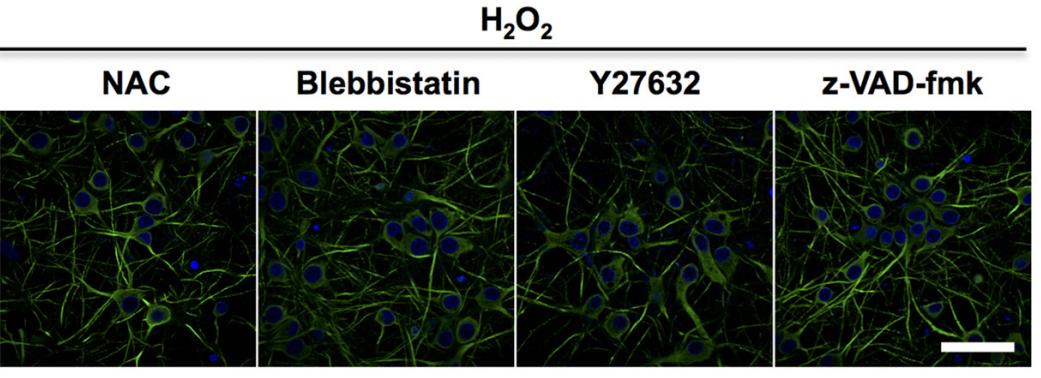

C

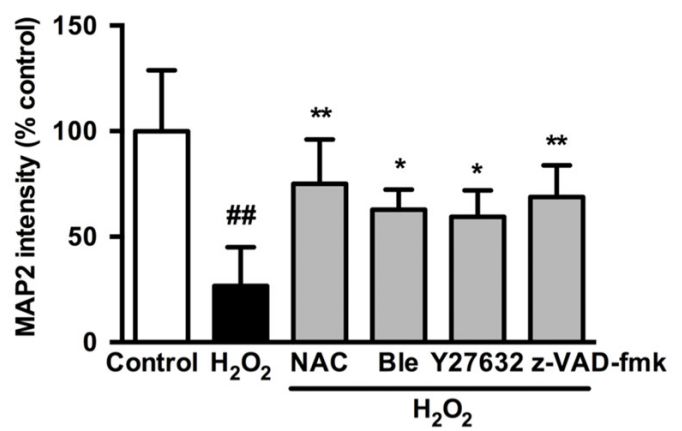

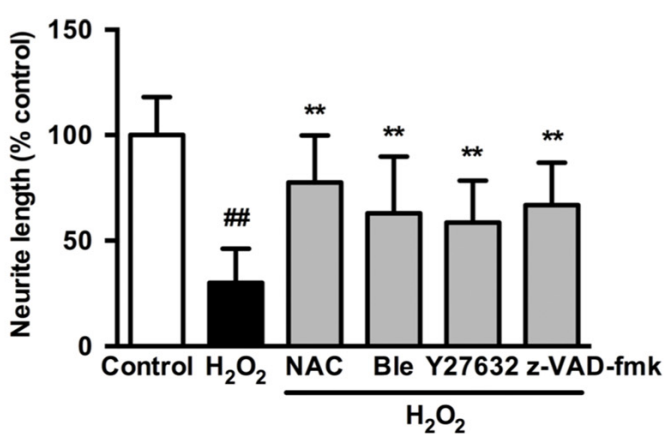

FIGURE 8 | Caspase, ROCK or myosin II inhibition decreases microtubule-associated protein 2 (MAP2) intensity and attenuates neurite retraction induced by $\mathbf{H}_{2} \mathbf{O}_{2}$ in neurons. (A) Effects of blebbistatin, Y27632 and z-VAD-fmk on neuronal MAP2 fluorescence (green) after $\mathrm{H}_{2} \mathrm{O}_{2}$ treatment. (B) Quantification of MAP2 fluorescence intensity in treated neurons. Bar, $40 \mu \mathrm{m}$. (C) Neurite length of neurons was measured using the Image software. The results were represented by percentage of neurite length compared to control. Results were expressed as mean \pm SD from three independent experiments (\#\# $P<0.01$ vs. control, ${ }^{*} P<0.05$ vs. $\mathrm{H}_{2} \mathrm{O}_{2}$-treated neurons, ${ }^{* *} \mathrm{P}<0.01$ vs. $\mathrm{H}_{2} \mathrm{O}_{2}$-treated neurons).

interaction of myosin IIB with actin filaments was more striking compared with that of myosin IIA under normal conditions. Therefore, decreased myosin IIB protein level could facilitate the binding between myosin IIA and actin filaments due to lack of competing with myosin IIB in neurons. Although myosin IIB levels were virtually not affected in PC12 cells, myosin IIB is reported to be less active than myosin IIA (Kelley et al., 1996), and bind with actin more slowly than myosin IIA (Kolega, 2003, 2006). Therefore, the differential localization and expression of myosin IIA and IIB, together with the spatial organization of actin filaments are critical to their actions (Beach and Hammer, 2015).

\section{Distinct Roles of Myosin IIA and IIB in Neuronal Cells}

Cellular activity, like growth and motility, is the resultant of a balance of forces, the mechanism involving two opposing processes: outgrowth and retraction. Each of these processes is regulated by the coordinated actions of one or more molecular motors (Chantler and Wylie, 2003; Hyland et al., 2014). It has reported that myosin IIA drives neurite retraction and maintains tensile adhesion (Wylie and Chantler, 2001), while myosin IIB drives outgrowth (Wylie et al., 1998). Knockdown of myosin IIA or IIB resulted in opposite morphological changes. Thus, the functions of myosin IIA and IIB counteracted each other. Our data indicated that loss of myosin IIA would result in a shift in the balance of myosin IIB-based outgrowth, while loss of myosin IIB resulted in the myosin IIA-mediated retraction. As myosin IIA derived large scale cellular contractile processes under oxidative stress-induced apoptosis, myosin IIB knockdown further increased the interaction of myosin IIA with actin and the related contractile forces generation, which caused cells more sensitive to oxidative stress and easier to undergo apoptosis.

It has been reported that myosin IIA depletion remarkably increases cell survival and cloning efficiency of human/mouse embryonic stem cells (h/mESCs; Walker et al., 2010). Myosin IIB, together with actin, constitute the actomyosin cytoskeleton that mediates contractility during TNFalpha-induced shrinkage, detachment and apoptosis in NIH 3T3 fibroblasts (Solinet and Vitale, 2008). Our results demonstrated that myosin IIA knockdown protected cells from cellular contraction, caspase-3 cleavage and apoptosis. We also showed for the first time that PC12 cells with myosin IIB knockdown had a higher proliferative activity than myosin IIA knockdown or control cells. It has been reported that cytokinesis is facilitated by the constriction of a cortical ring made up of myosin II and actin filaments in animal and fungal cells (Cheffings et al., 2016; Zambon et al., 2017). Actomyosin-drived cellular contractility is recognized as an important promoter for increased tumor number, growth and progression (Samuel et al., 2011). And myosin IIA stack occurs in the cleavage furrow of dividing cells and form the contractile ring to divide cells (Fenix et al., 2016). Therefore, 


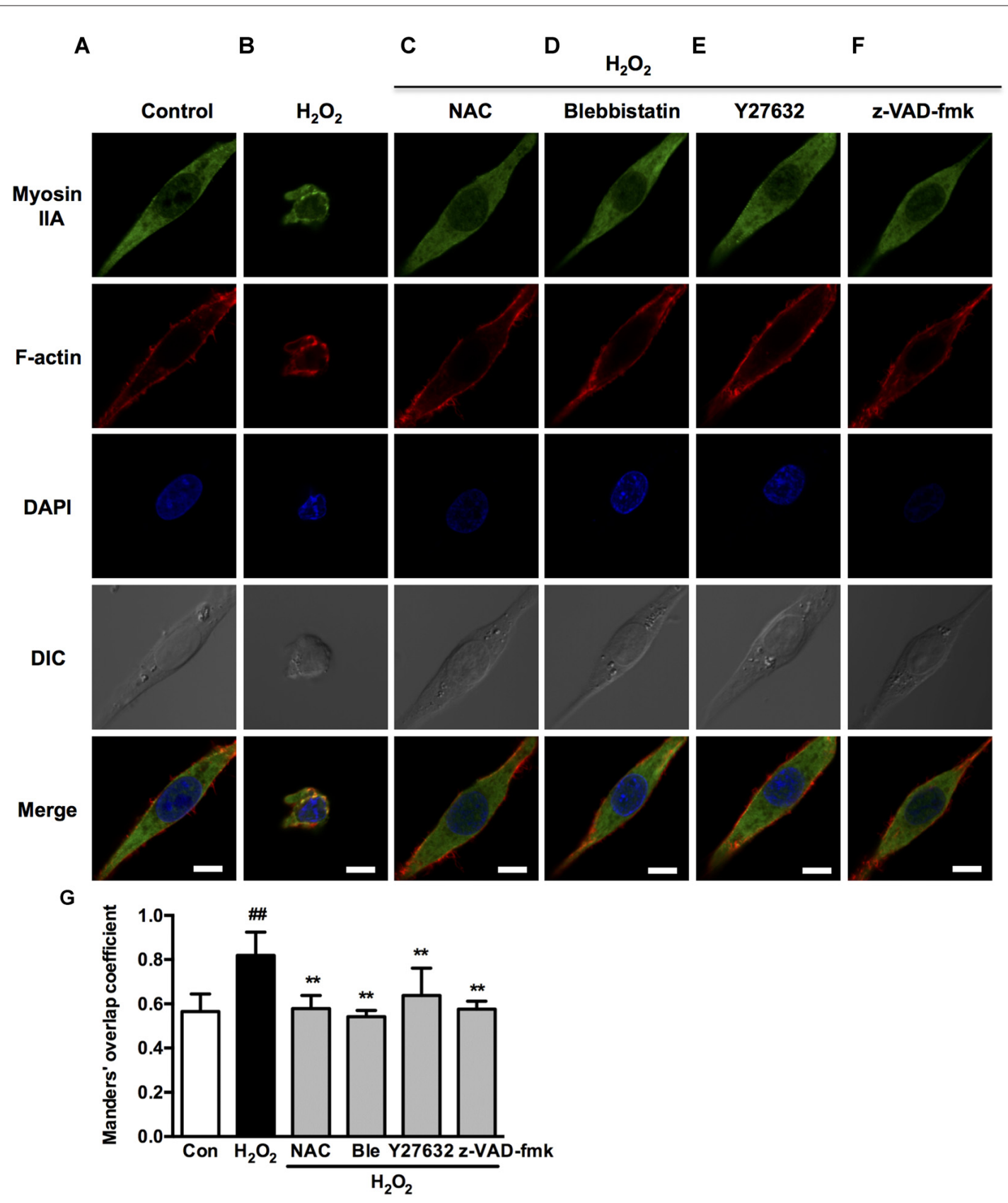

FIGURE 9 | Caspase, ROCK, myosin II inhibition attenuates $\mathbf{H}_{\mathbf{2}} \mathbf{O}_{\mathbf{2}}$-induced myosin IIA-actin interaction in PC12 cells. (A-F) PC12 cells were untreated or pretreated with $1 \mu \mathrm{M}$ blebbistatin, $10 \mu \mathrm{M}$ Y27632 or $10 \mu \mathrm{M}$ z-VAD-fmk for $1 \mathrm{~h}$ prior to $100 \mu \mathrm{M} \mathrm{H}_{2} \mathrm{O}_{2}$ treatment for $12 \mathrm{~h}$. Positive control was treated with NAC (500 $\mu \mathrm{M}$ ) for $1 \mathrm{~h}$ prior to $\mathrm{H}_{2} \mathrm{O}_{2}$ exposure. Myosin IIA (green), filamentous actin (red) and DAPI (blue) were detected by confocal microscope as indicated in Figure 2. Bar, $5 \mu \mathrm{m}$. (G) The quantitative co-localization of myosin IIA with F-actin was evaluated on basis of Manders' overlap coefficients. Results were expressed as mean \pm SD (\#\# $P<0.01$ vs. control, ${ }^{* *} P<0.01$ vs. $\mathrm{H}_{2} \mathrm{O}_{2}$-treated cells).

myosin IIB depletion might facilitate the myosin IIA-mediated cellular contractility that is essential for cytokinesis, causing increased PC12 cell number. These results indicated that myosin II regulates cell survival in an isoform and cell type specific manner.

Such an antagonistic relationship between these two motors on the morphology of PC12 cells and responses to oxidative stress may be an important mechanism by which the vectorial balance of forces is regulated during cellular growth and apoptosis. Myosin IIA knockout by CRISPR/Cas9 provides evidence of a central role for myosin IIA in cellular contractility-induced apoptosis under oxidative stress. This work also highlights the use of the CRISPR/Cas9 to study neuroscience and cytoskeletal functions. 


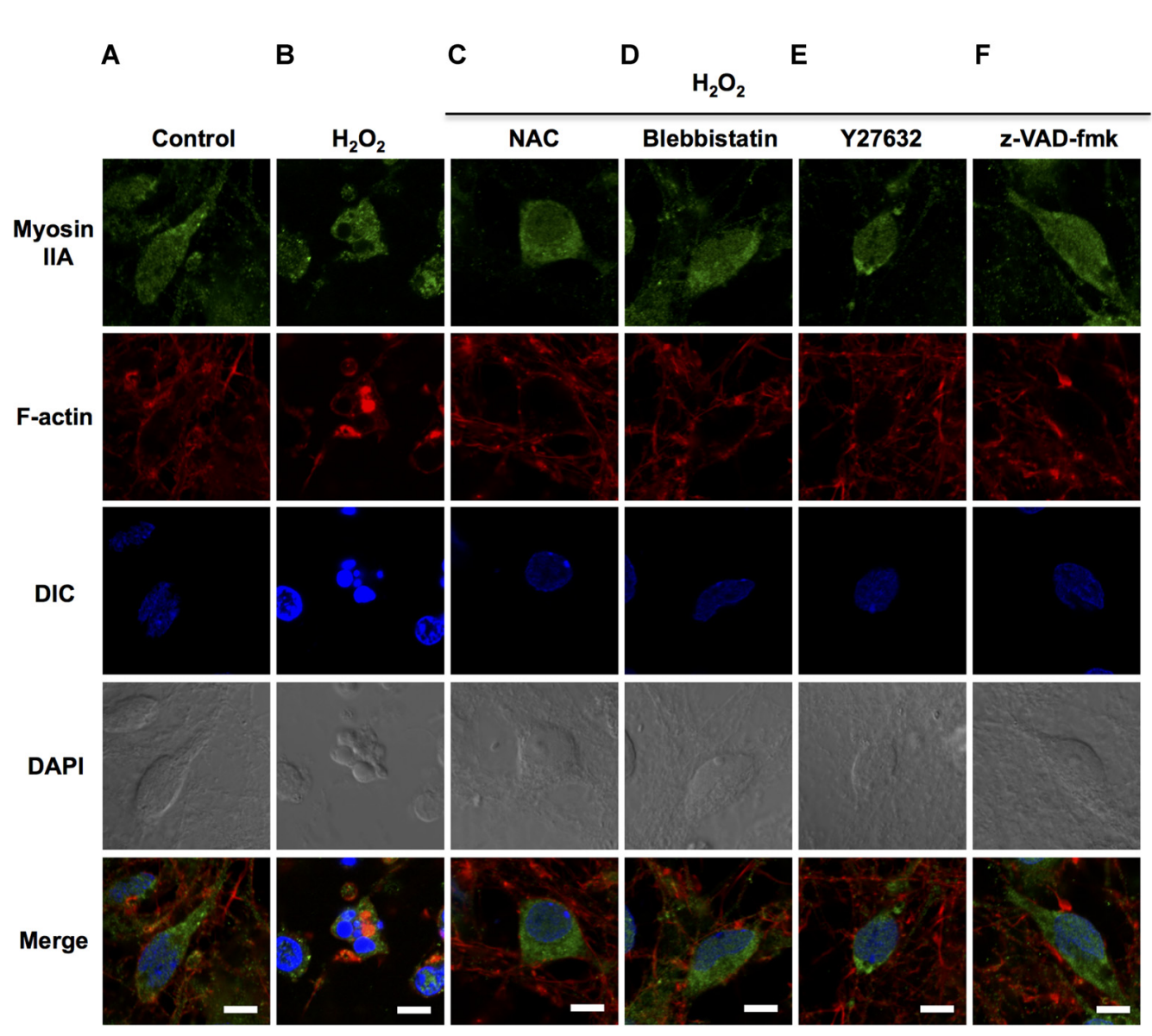

G

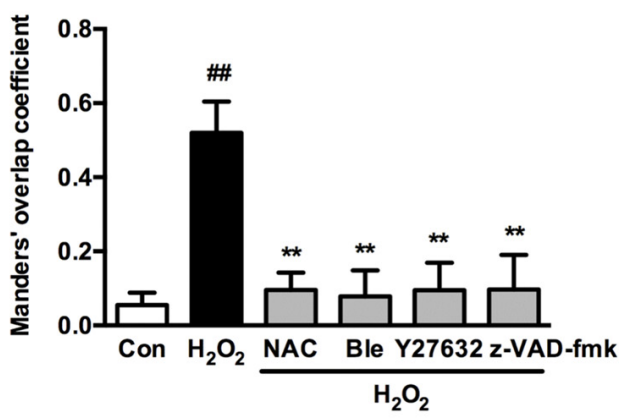

FIGURE 10 | Caspase, ROCK, myosin II inhibition attenuates $\mathbf{H}_{\mathbf{2}} \mathbf{O}_{\mathbf{2}}$-induced myosin IIA-actin interaction in neurons. (A-F) Neurons were untreated or pretreated with $1 \mu \mathrm{M}$ blebbistatin, $10 \mu \mathrm{M}$ Y27632 or $10 \mu \mathrm{M}$ z-VAD-fmk for $1 \mathrm{~h}$ prior to $100 \mu \mathrm{M} \mathrm{H} \mathrm{H}_{2}$ treatment for $12 \mathrm{~h}$. NAC (500 $\mu \mathrm{M}$ ) served as positive control. Myosin IIA (green), filamentous actin (red) and DAPI (blue) were detected by confocal microscope. Bar, $5 \mu \mathrm{m}$. (G) The quantitative co-localization of myosin IIA with F-actin was evaluated on the basis of Manders' overlap coefficients. Results were expressed as mean $\pm \mathrm{SD}(\# \#) \quad 0.01$ vs. control, ${ }^{* *} P<0.01$ vs. $\mathrm{H}_{2} \mathrm{O}_{2}$-treated cells).

\section{Oxidative Stress-induced Neuronal Apoptosis is Dependent on Actomyosin Contractility}

Activation of the myosin II motor through ATP hydrolysis and binding to actin filaments are required to initiate actomyosin contractility, which further facilitates cellular apoptosis (SariHassoun et al., 2016). Blebbistatin, a small molecular myosin inhibitor, exhibits high affinity and selectivity toward myosin II (Limouze et al., 2004; Allingham et al., 2005). Kinetic analysis shows that in the concentration range $0.5-5 \mu \mathrm{M}$, the inhibitor preferentially binds to the myosin-ADP-Pi complex and slows down phosphate release process. Thus, the inhibitor blocks the myosin II heads to interact with actin (Kovács et al., 2004). Several studies indicate the roles of blebbistatin in protection 


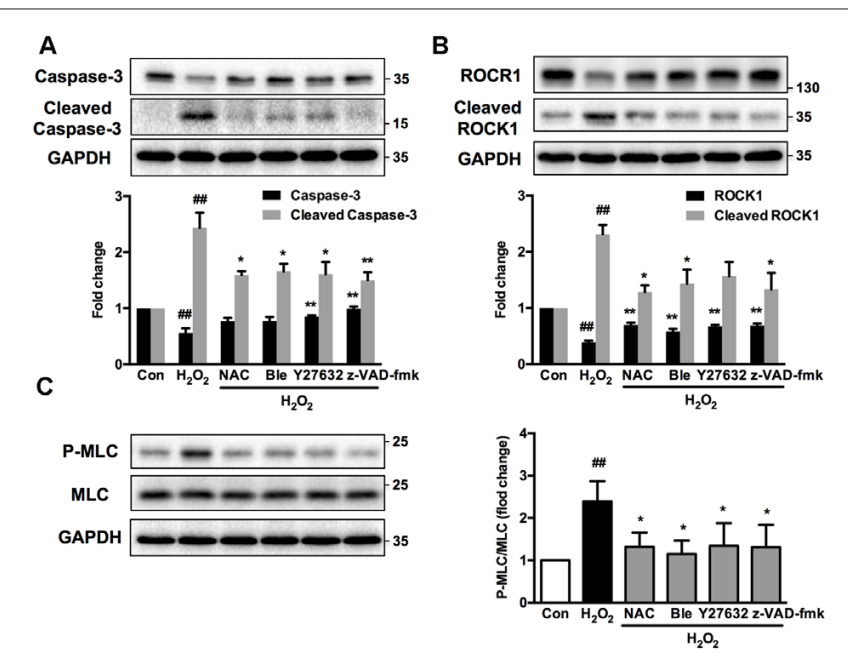

FIGURE 11 | Caspase, ROCK, myosin II inhibition attenuates $\mathrm{H}_{2} \mathrm{O}_{2}$-induced signaling pathway activation in PC12 cells. PC12 cells were untreated or pretreated with $1 \mu \mathrm{M}$ blebbistatin, $10 \mu \mathrm{M}$ Y27632 or $10 \mu \mathrm{M}$ z-VAD-fmk for $1 \mathrm{~h}$ prior to $100 \mu \mathrm{M} \mathrm{H}_{2} \mathrm{O}_{2}$ treatment for $12 \mathrm{~h}$. NAC served as positive control. Total cell lysates were prepared, subjected to Western blot analysis with antibodies to caspase-3, cleaved caspase-3 (A), ROCK1, cleaved ROCK1 (B), MLC and P-MLC (Ser-19) (C), and incubated with anti-GAPDH antibody as loading control. Results were expressed as mean \pm SD from three independent experiments ( ${ }^{\#} P<0.01$ vs. control, ${ }^{*} P<0.05$ vs. $\mathrm{H}_{2} \mathrm{O}_{2}$-treated cells, ${ }^{* *} P<0.01$ vs. $\mathrm{H}_{2} \mathrm{O}_{2}$-treated cells)

of damaged mammalian cells. Blebbistatin inhibits TNF $\alpha / \mathrm{CHX}$ induced apoptotic nuclear breakdown and membrane blebbing in fibroblasts (Croft et al., 2005). Inhibiting myosin II activity by blebbistatin markedly promotes growth cone invasion and accelerates axon growth rate on inhibitory substrates (Burnette et al., 2007; Hur et al., 2011). Although blebbistatin potently inhibits actin-myosin interaction, very little is known regarding its action in the organized contractile system of oxidative stressinduced neuronal apoptosis. Myosin II uses ATP to move along actin filaments, which forms actomyosin system in various cellular functions (Hartman and Spudich, 2012). Cytochalasin $\mathrm{D}$, a blocker of actin polymerization, disruptes actin filaments dynamics (Nair et al., 2008). Cytochalasin D treatment resists serum starvation-induced caspase-3 activation in NIH 3T3 cells by extracellularly activating gelatinase A, which interacts with integrin aVh3, eliciting survival signals mediated through ERK 1/2, p38 and SAPK/JNK pathways (Ailenberg and Silverman, 2003). Consistently, both blebbistatin and cytochalasin D prevented $\mathrm{H}_{2} \mathrm{O}_{2}$-induced activation of caspase-3, membrane blebbing and neurite retraction in neuronal cells. Our data demonstrate that the function of activated myosin II during neuronal apoptosis is associated with actin filament formation and actomyosin contractility.

\section{Myosin IIA-actin Interaction is involved in a Positive Feedback Loop with Caspase-3/ROCK1/MLC Phosphorylation}

Exogenous $\mathrm{H}_{2} \mathrm{O}_{2}$ influences the function of various proteins, such as kinases, phospholipases, transcription factors, ion channels, G proteins, et al. However, unlike other second messengers, the structure of $\mathrm{H}_{2} \mathrm{O}_{2}$ is too small and simple to interact with a specific protein target (Rhee et al., 2003). It has been reported that $\mathrm{H}_{2} \mathrm{O}_{2}$ induces neuronal apoptosis through various signaling pathway, such as nuclear factor $-\kappa \mathrm{B}$, JNK/ERK (Liu et al., 2017), Cdc42/MLK3/MKK7/JNK3 pathway (Wang et al., 2017), P53, mitochondria-related Bax and Bcl-2 (Sohn et al., 2016), Akt/H2A phosphorylation (Park et al., 2016), et al. In out research, time-course study revealed that $\mathrm{H}_{2} \mathrm{O}_{2}$ activated caspase-3, ROCK1 and MLC in chronological sequence. Thus, $\mathrm{H}_{2} \mathrm{O}_{2}$ activated caspase- 3 through upstream pathways and then activated caspase- 3 mediated ROCK1 and MLC activation. However, the upstream signaling of caspase- 3 still needs to be further investigated.

It has been previously demonstrated that caspase/ROCKmediated MLC phosphorylation and the mitochondrial signaling axis regulate cell apoptosis (Liu et al., 2013; Shen et al., 2015b). Our findings extended previous observations by showing that activated caspase-3, ROCK1 and phosphorylated MLC were specifically associated with the myosin IIA-actin cytoskeletal system. Disruption of myosin IIA-actin contraction is the mechanism by which caspase or ROCK inhibitors decreased apoptosis and membrane blebbing of neuronal cells. Interestingly, inhibition of myosin IIA-actin contraction by blebbistatin, myosin IIA knockdown, knockout or cytochalasin D in turn inhibited caspase-3 activation. Blebbistatin also inhibited ROCK1 activation and MLC phosphorylation, which was similar with the effects of Y27632 and z-VAD-fmk. These results indicated that myosin IIA and its interaction with actin filaments could regulate caspase-3/ROCK1/MLC phosphorylation in a positive feedback manner, which has numerous implications. Once activated, this positive feedback loop may be an important mechanism to amplify and sustain actomyosin contractility, signaling cascade activation and ultimate apoptosis. This architecture also explains the observation that disruption of caspase, ROCK, myosin IIA or actin functionally disrupted the entire mechanical system and signaling pathway, resulting in similar phenotypes such as decreased membrane blebbing, apoptosis and neurite retraction.

It has been suggested an existence of a feedback loop between cytoskeletal tension, adhesion maturation and ROCK signaling that contributes to numerous mechanochemical processes (Bhadriraju et al., 2007). Under the treatment of rotenone, PUMA, Bcl-XL and p53 form a positive feedback amplification loop to increase the apoptosis sensitivity (Shi et al., 2014). Additionally, downstream caspase-3 reinforces Bak activation and the release of AIF and endoG through positive loops, which sensitize cancer cells to the treatment with genistein (Guo et al., 2015). The numerous feedback loops between cytoskeletal, apoptotic and mechanical functions of cells and the related signaling pathway highlight the complexity of pathological and physiological mechanisms in cells. Other studies have also reported that myosin IIA knockdown or blebbistatin pretreatment remarkably increase cell survival and cloning efficiency of embryonic stem cells (Walker et al., 2010). Moreover, inhibition of actin polymerization by cytochalasin $\mathrm{D}$ inhibits thrombin-induced activation of caspase- 3 and caspase- 9 


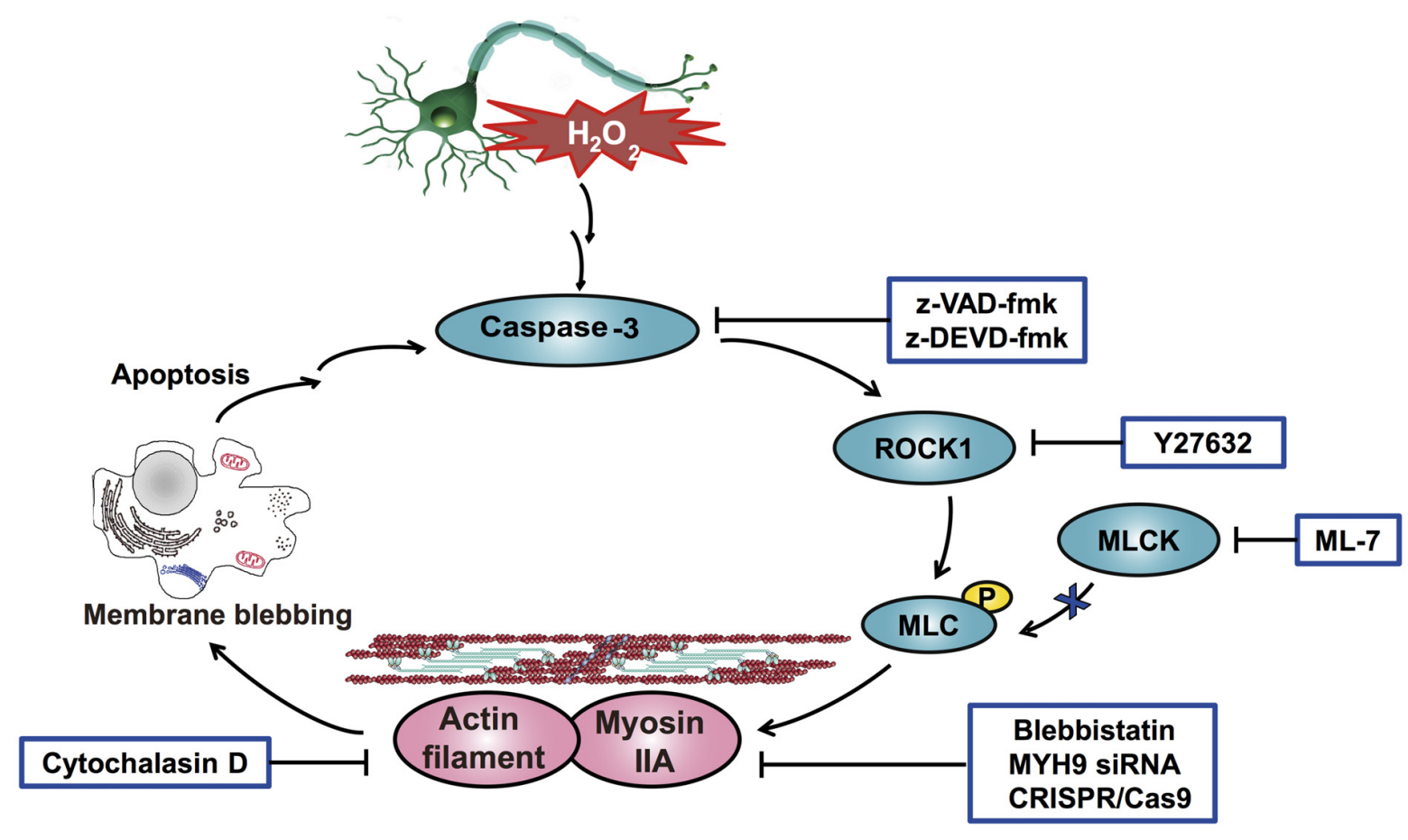

FIGURE 12 | Schematic overview of the proposed mechanism for $\mathrm{H}_{2} \mathrm{O}_{2}$-induced neuronal apoptosis. $\mathrm{H}_{2} \mathrm{O}_{2}$ induces caspase-3 activation through upstream signaling pathways and then stimulates the cleavage of ROCK1, which promotes the phosphorylation of MLC (Ser-19). Phosphorylated MLC activates myosin IIA and facilitates its association with actin filaments. Consequently, the increased interaction of myosin IIA and actin generates the actomyosin contractility, which initiates membrane blebbing and neuronal apoptosis. In addition, the increased interaction of myosin $I \mathrm{~A}$ and actin amplifies and sensitizes $\mathrm{H}_{2} \mathrm{O}_{2}$-induced apoptosis. Collectively, a positive feedback loop of caspase-3/ROCK1/MLC/myosin IIA-actin contractility mediates $\mathrm{H}_{2} \mathrm{O}_{2}$-induced neuronal apoptosis.

in human platelets (Ben Amor et al., 2006). However, how the cellular contractile forces regulate caspase- 3 activity has not been fully elucidated. Investigating these mechanisms will be important to us to understand how cells coordinate the mechanical and biochemical events.

\section{Future Direction of the Research}

As our data support a regulatory loop between myosin IIA and caspase-3/ROCK1/MLC pathway, this raises the question about how the cell specifically regulates myosin IIB activity. It has been shown that myosin IIB is activated upstream by PKC, PAK1 or Rac, which have been shown to regulate the phosphorylation and cellular localization of myosin IIB and induce neurite outgrowth (Even-Faitelson et al., 2005; Solinet and Vitale, 2008). Regulation of myosin IIA and IIB by distinct signaling pathways might be an explanation for myosin II isoforms performing different functions at different places in cells. Clearly, additional work is required to fully understand the specific roles of myosin IIA and IIB, and how the two isoforms are distinctly regulated. In addition, myosin IIA and IIB share $77 \%$ identity at the amino acid level, they are believed to have considerable functional overlap in certain circumstances (Bao et al., 2007). Despite our observations that myosin IIA and IIB perform unique cellular functions, it still needs further research on the complementary actions and how the two isoforms influence each other in regulating neuronal function and apoptosis.
In conclusion, we identified the distinct functions of the two highly conserved myosin II motors in oxidative stressinduced neuronal apoptosis. Myosin IIA, rather than myosin IIB, constitutes a continuous mechanical link with actin filaments, and is required to develop contractile forces and membrane blebbing during $\mathrm{H}_{2} \mathrm{O}_{2}$-induced neuronal apoptosis. Myosin IIA is also involved in a positive feedback loop that links caspase-3/ROCK1/MLC signaling axis. Understanding the cytoskeletal basis of neuronal cells would be helpful to clarify the cellular mechanisms underlying the biochemical, mechanistic and morphological changes induced by oxidative stress, and to develop therapeutics for neuronal diseases.

\section{AUTHOR CONTRIBUTIONS}

JK conceived and supervised the study. YW and JK designed experiments. YW and YX performed the experiments. YZ, GC, MY, NJ and BY provided facilities. YW, YX, YZ, BY, ZC and $\mathrm{JK}$ analyzed and interpreted the data. YW, QL and $Z G$ wrote and revised the manuscript. $\mathrm{ZC}$ and $\mathrm{JK}$ reviewed the manuscript.

\section{FUNDING}

This work was supported by the National Natural Science Foundation of China (No. 81274004) and the Fundamental 
Research Funds for the Central Universities (No. 2410724), a project funded by the Priority Academic Program Development of Jiangsu Higher Education Institution.

\section{ACKNOWLEDGMENTS}

Thanks are due to Kaixuan Lin in Stem Cell Center, Yale University for assistance with the language help and Xiaonan $\mathrm{Ma}$

\section{REFERENCES}

Ailenberg, M., and Silverman, M. (2003). Cytochalasin D disruption of actin filaments in 3T3 cells produces an anti-apoptotic response by activating gelatinase A extracellularly and initiating intracellular survival signals. Biochim. Biophys. Acta 1593, 249-258. doi: 10.1016/s0167-4889(02) 00395-6

Allingham, J. S., Smith, R., and Rayment, I. (2005). The structural basis of blebbistatin inhibition and specificity for myosin II. Nat. Struct. Mol. Biol. 12, 378-379. doi: 10.1038/nsmb908

Bao, J., Ma, X., Liu, C., and Adelstein, R. S. (2007). Replacement of nonmuscle myosin II-B with II-A rescues brain but not cardiac defects in mice. J. Biol. Chem. 282, 22102-22111. doi: 10.1074/jbc.M702731200

Beach, J. R., and Hammer, J. A. III (2015). Myosin II isoform co-assembly and differential regulation in mammalian systems. Exp. Cell Res. 334, 2-9. doi: 10.1016/j.yexcr.2015.01.012

Ben Amor, N., Pariente, J. A., Salido, G. M., Bartegi, A., and Rosado, J. A. (2006). Caspases 3 and 9 are translocated to the cytoskeleton and activated by thrombin in human platelets. Evidence for the involvement of PKC and the actin filament polymerization. Cell. Signal. 18, 1252-1261. doi: 10.1016/j.cellsig.2005. 10.002

Bhadriraju, K., Yang, M., Alom Ruiz, S., Pirone, D., Tan, J., and Chen, C. S. (2007). Activation of ROCK by RhoA is regulated by cell adhesion, shape, and cytoskeletal tension. Exp. Cell Res. 313, 3616-3623. doi: 10.1016/j.yexcr.2007. 07.002

Bolte, S., and Cordelières, F. P. (2006). A guided tour into subcellular colocalization analysis in light microscopy. J. Microsc. 224, 213-232. doi: 10.1111/j.1365-2818.2006.01706.x

Bresnick, A. R. (1999). Molecular mechanisms of nonmuscle myosin-II regulation. Curr. Opin. Cell Biol. 11, 26-33. doi: 10.1016/s0955-0674(99)80004-0

Burnette, D. T., Schaefer, A. W., Ji, L., Danuser, G., and Forscher, P. (2007). Filopodial actin bundles are not necessary for microtubule advance into the peripheral domain of Aplysia neuronal growth cones. Nat. Cell Biol. 9, 1360-1369. doi: 10.1038/ncb1655

Cao, Z., Li, X., Zou, X., Greenwood, M., Gerwick, W. H., and Murray, T. F. (2015). Involvement of JNK and caspase activation in hoiamide A-induced neurotoxicity in neocortical neurons. Mar. Drugs 13, 903-919. doi: $10.3390 / \mathrm{md} 13020903$

Chantler, P. D., and Wylie, S. R. (2003). Elucidation of the separate roles of myosins IIA and IIB during neurite outgrowth, adhesion and retraction. IEE Proc. Nanobiotechnol. 150, 111-125. doi: 10.1049/ip-nbt:20031076

Cheffings, T. H., Burroughs, N. J., and Balasubramanian, M. K. (2016). Actomyosin ring formation and tension generation in eukaryotic cytokinesis. Curr. Biol. 26, R719-R737. doi: 10.1016/j.cub.2016.06.071

Coleman, M. L., Sahai, E. A., Yeo, M., Bosch, M., Dewar, A., and Olson, M. F. (2001). Membrane blebbing during apoptosis results from caspase-mediated activation of ROCK I. Nat. Cell Biol. 3, 339-345. doi: 10.1038/35070009

Croft, D. R., Coleman, M. L., Li, S., Robertson, D., Sullivan, T., Stewart, C. L., et al. (2005). Actin-myosin-based contraction is responsible for apoptotic nuclear disintegration. J. Cell Biol. 168, 245-255. doi: 10.1083/jcb.200409049

Eitaki, M., Yamamori, T., Meike, S., Yasui, H., and Inanami, O. (2012). Vincristine enhances amoeboid-like motility via GEF-H1/RhoA/ROCK/Myosin light chain signaling in MKN45 cells. BMC Cancer 12:469. doi: 10.1186/1471-2407-12-469

Even-Faitelson, L., Rosenberg, M., and Ravid, S. (2005). PAK1 regulates myosin II-B phosphorylation, filament assembly, localization and cell chemotaxis. Cell. Signal. 17, 1137-1148. doi: 10.1016/j.cellsig.2004.12.015 in Cellular and Molecular Biology Center, China Pharmaceutical University for confocal microscopy.

\section{SUPPLEMENTARY MATERIAL}

The Supplementary Material for this article can be found online at: http://journal.frontiersin.org/article/10.3389/fnmol. 2017.00075/full\#supplementary-material

Even-Ram, S., Doyle, A. D., Conti, M. A., Matsumoto, K., Adelstein, R. S., and Yamada, K. M. (2007). Myosin IIA regulates cell motility and actomyosinmicrotubule crosstalk. Nat. Cell Biol. 9, 299-309. doi: 10.1038/ncb1540

Fenix, A. M., Taneja, N., Buttler, C. A., Lewis, J., Van Engelenburg, S. B., Ohi, R., et al. (2016). Expansion and concatenation of non-muscle myosin IIA filaments drive cellular contractile system formation during interphase and mitosis. Mol. Biol. Cell 27, 1465-1478. doi: 10.1091/mbc.E15-10-0725

Gordon-Weeks, P. R., and Fournier, A. E. (2014). Neuronal cytoskeleton in synaptic plasticity and regeneration. J. Neurochem. 129, 206-212. doi: $10.1111 /$ jnc. 12502

Guo, W., Zhang, Y., Ling, Z., Liu, X., Zhao, X., Yuan, Z., et al. (2015). Caspase3 feedback loop enhances Bid-induced AIF/endoG and Bak activation in Bax and p53-independent manner. Cell Death Dis. 6:e1919. doi: 10.1038/cddis. 2015.276

Hartman, M. A., and Spudich, J. A. (2012). The myosin superfamily at a glance. J. Cell Sci. 125, 1627-1632. doi: 10.1242/jcs.094300

Hayashi-Takagi, A., Araki, Y., Nakamura, M., Vollrath, B., Duron, S. G., Yan, Z., et al. (2014). PAKs inhibitors ameliorate schizophrenia-associated dendritic spine deterioration in vitro and in vivo during late adolescence. Proc. Natl. Acad. Sci. U S A 111, 6461-6466. doi: 10.1073/pnas.1321109111

Hur, E.-M., Yang, I. H., Kim, D.-H., Byun, J., Saijilafu, Xu, W.-L., et al. (2011). Engineering neuronal growth cones to promote axon regeneration over inhibitory molecules. Proc. Natl. Acad. Sci. U S A 108, 5057-5062. doi: 10.1073/pnas.1011258108

Hyland, C., Mertz, A. F., Forscher, P., and Dufresne, E. (2014). Dynamic peripheral traction forces balance stable neurite tension in regenerating Aplysia bag cell neurons. Sci. Rep. 4:4961. doi: 10.1038/srep04961

Kamat, P. K., Kalani, A., Rai, S., Swarnkar, S., Tota, S., Nath, C., et al. (2016). Mechanism of oxidative stress and synapse dysfunction in the pathogenesis of Alzheimer's disease: understanding the therapeutics strategies. Mol. Neurobiol. 53, 648-661. doi: 10.1007/s12035-014-9053-6

Kelley, C. A., Sellers, J. R., Gard, D. L., Bui, D., Adelstein, R. S., and Baines, I. C. (1996). Xenopus nonmuscle myosin heavy chain isoforms have different subcellular localizations and enzymatic activities. J. Cell Biol. 134, 675-687. doi: $10.1083 /$ jcb.134.3.675

Kimura, K., Ito, M., Amano, M., Chihara, K., Fukata, Y., Nakafuku, M., et al. (1996). Regulation of myosin phosphatase by Rho and Rho-associated kinase (Rho-kinase). Science 273, 245-248. doi: 10.1126/science.273.5272.245

Kolega, J. (2003). Asymmetric distribution of myosin IIB in migrating endothelial cells is regulated by a rho-dependent kinase and contributes to tail retraction. Mol. Biol. Cell 14, 4745-4757. doi: 10.1091/mbc.E03-04-0205

Kolega, J. (2006). The role of myosin II motor activity in distributing myosin asymmetrically and coupling protrusive activity to cell translocation. Mol. Biol. Cell 17, 4435-4445. doi: 10.1091/mbc.E06-05-0431

Kovács, M., Tóth, J., Hetányi, C., Málnási-Csizmadia, A., and Sellers, J. R. (2004). Mechanism of blebbistatin inhibition of myosin II. J. Biol. Chem. 279, 35557-35563. doi: 10.1074/jbc.M405319200

Lai, J. M., Hsieh, C. L., and Chang, Z. F. (2003). Caspase activation during phorbol ester-induced apoptosis requires ROCK-dependent myosin-mediated contraction. J. Cell Sci. 116, 3491-3501. doi: 10.1242/jcs.00660

Landino, J., and Ohi, R. (2016). The timing of midzone stabilization during cytokinesis depends on myosin II activity and an interaction between INCENP and actin. Curr. Biol. 26, 698-706. doi: 10.1016/j.cub.2016.01.018

Limouze, J., Straight, A. F., Mitchison, T., and Sellers, J. R. (2004). Specificity of blebbistatin, an inhibitor of myosin II. J. Muscle Res. Cell Motil. 25, 337-341. doi: 10.1007/s10974-004-6060-7 
Liu, J. Y., Guo, F., Wu, H. L., Wang, Y., and Liu, J. S. (2017). Midazolam anesthesia protects neuronal cells from oxidative stress-induced death via activation of the JNK-ERK pathway. Mol. Med. Rep. 15, 169-179. doi: 10.3892/mmr. 2016.6031

Liu, L., Li, G., Li, Q., Jin, Z., Zhang, L., Zhou, J., et al. (2013). Triptolide induces apoptosis in human leukemia cells through caspase-3-mediated ROCK1 activation and MLC phosphorylation. Cell Death Dis. 4:e941. doi: $10.1038 /$ cddis.2013.469

Medeiros, N. A., Burnette, D. T., and Forscher, P. (2006). Myosin II functions in actin-bundle turnover in neuronal growth cones. Nat. Cell Biol. 8, 215-226. doi: $10.1038 /$ ncb1367

Miñambres, R., Guasch, R. M., Perez-Aragó, A., and Guerri, C. (2006). The RhoA/ROCK-I/MLC pathway is involved in the ethanol-induced apoptosis by anoikis in astrocytes. J. Cell Sci. 119, 271-282. doi: 10.1242/jcs.02723

Nair, U. B., Joel, P. B., Wan, Q., Lowey, S., Rould, M. A., and Trybus, K. M. (2008). Crystal structures of monomeric actin bound to cytochalasin D. J. Mol. Biol. 384, 848-864. doi: 10.1016/j.jmb.2008.09.082

Ndozangue-Touriguine, O., Hamelin, J., and Bréard, J. (2008). Cytoskeleton and apoptosis. Biochem. Pharmacol. 76, 11-18. doi: 10.1016/j.bcp.2008.03.016

Nilius, B., Prenen, J., Walsh, M. P., Carton, I., Bollen, M., Droogmans, G., et al. (2000). Myosin light chain phosphorylation-dependent modulation of volume-regulated anion channels in macrovascular endothelium. FEBS Lett. 466, 346-350. doi: 10.1016/s0014-5793(00)01097-8

Ozkan, E. D., Aceti, M., Creson, T. K., Rojas, C. S., Hubbs, C. R., McGuire, M. N., et al. (2015). Input-specific regulation of hippocampal circuit maturation by non-muscle myosin IIB. J. Neurochem. 134, 429-444. doi: 10.1111/jnc. 13146

Park, J. H., Kim, C. K., Lee, S. B., Lee, K. H., Cho, S. W., and Ahn, J. Y. (2016). Akt attenuates apoptotic death through phosphorylation of H2A under hydrogen peroxide-induced oxidative stress in PC12 cells and hippocampal neurons. Sci. Rep. 6:21857. doi: 10.1038/srep21857

Pool, M., Rambaldi, I., Durafourt, B. A., Wright, M. C., Antel, J. P., Bar-Or, A., et al. (2011). Myeloid lineage cells inhibit neurite outgrowth through a myosin II-dependent mechanism. J. Neuroimmunol. 237, 101-105. doi: 10.1016/j. jneuroim.2011.06.004

Rex, C. S., Gavin, C. F., Rubio, M. D., Kramar, E. A., Chen, L. Y., Jia, Y., et al. (2010). Myosin IIb regulates actin dynamics during synaptic plasticity and memory formation. Neuron 67, 603-617. doi: 10.1016/j.neuron.2010.07.016

Rhee, S. G., Chang, T. S., Bae, Y. S., Lee, S. R., and Kang, S. W. (2003). Cellular regulation by hydrogen peroxide. J. Am. Soc. Nephrol. 14, S211-S215. doi: 10.1097/01.asn.0000077404.45564.7e

Ryu, J., Liu, L., Wong, T. P., Wu, D. C., Burette, A., Weinberg, R., et al. (2006). A critical role for myosin IIb in dendritic spine morphology and synaptic function. Neuron 49, 175-182. doi: 10.1016/j.neuron.2005.12.017

Samuel, M. S., Lopez, J. I., McGhee, E. J., Croft, D. R., Strachan, D., Timpson, P., et al. (2011). Actomyosin-mediated cellular tension drives increased tissue stiffness and beta-catenin activation to induce epidermal hyperplasia and tumor growth. Cancer Cell 19, 776-791. doi: 10.1016/j.ccr.2011. 05.008

Sari-Hassoun, M., Clement, M. J., Hamdi, I., Bollot, G., Bauvais, C., Joshi, V., et al. (2016). Cucurbitacin I elicits the formation of actin/phospho-myosin II co-aggregates by stimulation of the RhoA/ROCK pathway and inhibition of LIM-kinase. Biochem. Pharmacol. 102, 45-63. doi: 10.1016/j.bcp.2015. 12.013

Schafer, D. P., Jha, S., Liu, F., Akella, T., McCullough, L. D., and Rasband, M. N. (2009). Disruption of the axon initial segment cytoskeleton is a new mechanism for neuronal injury. J. Neurosci. 29, 13242-13254. doi: 10.1523/JNEUROSCI. 3376-09.2009

Sebbagh, M., Renvoize, C., Hamelin, J., Riché, N., Bertoglio, J., and Bréard, J. (2001). Caspase-3-mediated cleavage of ROCK I induces MLC phosphorylation and apoptotic membrane blebbing. Nat. Cell Biol. 3, 346-352. doi: 10.1038/35070019

Shelton, M. A., Newman, J. T., Gu, H., Sampson, A. R., Fish, K. N., MacDonald, M. L., et al. (2015). Loss of microtubule-associated protein 2 immunoreactivity linked to dendritic spine loss in schizophrenia. Biol. Psychiatry 78, 374-385. doi: 10.1016/j.biopsych.2014.12.029

Shen, K., Wang, Y., Zhang, Y., Zhou, H., Song, Y., Cao, Z., et al. (2015a). Cocktail of four active components derived from sheng mai san inhibits hydrogen peroxide-induced PC12 cell apoptosis linked with the caspase3/ROCK1/MLC pathway. Rejuvenation Res. 18, 517-527. doi: 10.1089/rej. 2015.1697

Shen, K., Xie, J., Wang, H., Zhang, H., Yu, M., Lu, F., et al. (2015b). Cambogin induces caspase-independent apoptosis through the ROS/JNK pathway and epigenetic regulation in breast cancer cells. Mol. Cancer Ther. 14, 1738-1749. doi: 10.1158/1535-7163.MCT-14-1048

Shi, Y. L., Feng, S., Chen, W., Hua, Z. C., Bian, J. J., and Yin, W. (2014). Mitochondrial inhibitor sensitizes non-small-cell lung carcinoma cells to TRAIL-induced apoptosis by reactive oxygen species and Bcl$\mathrm{X}(\mathrm{L}) / \mathrm{p} 53$-mediated amplification mechanisms. Cell Death Dis. 5:e1579. doi: $10.1038 /$ cddis. 2014.547

Simons, M., Wang, M., McBride, O. W., Kawamoto, S., Yamakawa, K., Gdula, D., et al. (1991). Human nonmuscle myosin heavy chains are encoded by two genes located on different chromosomes. Circ. Res. 69, 530-539. doi: 10.1161/01.res. 69.2.530

Sohn, E. J., Shin, M. J., Eum, W. S., Kim, D. W., Yong, J. I., Ryu, E. J., et al. (2016). Tat-NOL3 protects against hippocampal neuronal cell death induced by oxidative stress through the regulation of apoptotic pathways. Int. J. Mol. Med. 38, 225-235. doi: 10.3892/ijmm.2016.2596

Solecki, D. J., Trivedi, N., Govek, E. E., Kerekes, R. A., Gleason, S. S., and Hatten, M. E. (2009). Myosin II motors and F-actin dynamics drive the coordinated movement of the centrosome and soma during CNS glialguided neuronal migration. Neuron 63, 63-80. doi: 10.1016/j.neuron.2009. 05.028

Solinet, S., and Vitale, M. L. (2008). Isoform B of myosin II heavy chain mediates actomyosin contractility during TNF $\alpha$-induced apoptosis. J. Cell Sci. 121, 1681-1692. doi: $10.1242 /$ jcs. 022640

Totsukawa, G., Yamakita, Y., Yamashiro, S., Hartshorne, D. J., Sasaki, Y., and Matsumura, F. (2000). Distinct roles of ROCK (Rho-kinase) and MLCK in spatial regulation of MLC phosphorylation for assembly of stress fibers and focal adhesions in 3T3 fibroblasts. J. Cell Biol. 150, 797-806. doi: 10.1083/jcb. 150.4.797

Turney, S. G., Ahmed, M., Chandrasekar, I., Wysolmerski, R. B., Goeckeler, Z. M., Rioux, R. M., et al. (2016). Nerve growth factor stimulates axon outgrowth through negative regulation of growth cone actomyosin restraint of microtubule advance. Mol. Biol. Cell 27, 500-517. doi: 10.1091/mbc.E15-090636

Vicente-Manzanares, M., Zareno, J., Whitmore, L., Choi, C. K., and Horwitz, A. F. (2007). Regulation of protrusion, adhesion dynamics and polarity by myosins IIA and IIB in migrating cells. J. Cell Biol. 176, 573-580. doi: 10.1083/jcb. 200612043

Volpe, M., and Paneni, F. (2015). Shooting vascular oxidative stress: new hopes for stroke patients? Eur. Heart J. 36, 1573-1575. doi: 10.1093/eurheartj/ ehv175

Walker, A., Su, H., Conti, M. A., Harb, N., Adelstein, R. S., and Sato, N. (2010). Non-muscle myosin II regulates survival threshold of pluripotent stem cells. Nat. Commun. 1:71. doi: 10.1038/ncomms1074

Wang, Y., Liu, Q., Xu, Y. Q., Zhang, Y. Y., Lv, Y. N., Tan, Y. S., et al. (2016). Ginsenoside Rg1 protects against oxidative stress-induced neuronal apoptosis through myosin IIA-actin related cytoskeletal reorganization. Int. J. Biol. Sci. 12, 1341-1356. doi: 10.7150/ijbs. 15992

Wang, S., Zhang, T., Yang, Z., Lin, J., Cai, B., Ke, Q., et al. (2017). Heme oxygenase-1 protects spinal cord neurons from hydrogen peroxide-induced apoptosis via suppression of Cdc42/MLK3/MKK7/JNK3 signaling. Apoptosis 22, 449-462. doi: 10.1007/s10495-016-1329-z

Wickman, G. R., Julian, L., Mardilovich, K., Schumacher, S., Munro, J., Rath, N., et al. (2013). Blebs produced by actin-myosin contraction during apoptosis release damage-associated molecular pattern proteins before secondary necrosis occurs. Cell Death Differ. 20, 1293-1305. doi: 10.1038/cdd.2013.69

Wylie, S. R., and Chantler, P. D. (2001). Separate but linked functions of conventional myosins modulate adhesion and neurite outgrowth. Nat. Cell Biol. 3, 88-92. doi: 10.1038/35050613

Wylie, S. R., and Chantler, P. D. (2003). Myosin IIA drives neurite retraction. Mol. Biol. Cell 14, 4654-4666. doi: 10.1091/mbc.E03-03-0187

Wylie, S. R., Wu, P. J., Patel, H., and Chantler, P. D. (1998). A conventional myosin motor drives neurite outgrowth. Proc. Natl. Acad. Sci. U S A 95, 12967-12972. doi: $10.1073 /$ pnas.95.22.12967 
Yu, P., Santiago, L. Y., Katagiri, Y., and Geller, H. M. (2012). Myosin II activity regulates neurite outgrowth and guidance in response to chondroitin sulfate proteoglycans. J. Neurochem. 120, 1117-1128. doi: 10.1111/j.1471-4159.2011. 07638.x

Zambon, P., Palani, S., Kamnev, A., and Balasubramanian, M. K. (2017). Myo2p is the major motor involved in actomyosin ring contraction in fission yeast. Curr. Biol. 27, R99-R100. doi: 10.1016/j.cub.2016. 12.024

Zhou, M., and Wang, Y. L. (2008). Distinct pathways for the early recruitment of myosin II and actin to the cytokinetic furrow. Mol. Biol. Cell 19, 318-326. doi: 10.1091/mbc.E07-08-0783
Conflict of Interest Statement: The authors declare that the research was conducted in the absence of any commercial or financial relationships that could be construed as a potential conflict of interest.

Copyright (c) 2017 Wang, Xu, Liu, Zhang, Gao, Yin, Jiang, Cao, Yu, Cao and Kou. This is an open-access article distributed under the terms of the Creative Commons Attribution License (CC BY). The use, distribution and reproduction in other forums is permitted, provided the original author(s) or licensor are credited and that the original publication in this journal is cited, in accordance with accepted academic practice. No use, distribution or reproduction is permitted which does not comply with these terms. 